NBER WORKING PAPER SERIES

\title{
IMPERFECT FINANCIAL MARKETS AND SHAREHOLDER INCENTIVES IN PARTIAL AND GENERAL EQUILIBRIUM
}

\author{
Elias Albagli \\ Christian Hellwig \\ Aleh Tsyvinski \\ Working Paper 23419 \\ http://www.nber.org/papers/w23419 \\ NATIONAL BUREAU OF ECONOMIC RESEARCH \\ 1050 Massachusetts Avenue \\ Cambridge, MA 02138 \\ May 2017
}

We thank Effi Benmelech, Bruno Biais, John Campbell, V.V. Chari, Amil Dasgupta, Kinda Hachem, Zhiguo He, Ulrich Hege, Peter Kondor, Guido Lorenzoni, Markus Brunnermeier, Stephen Morris, Jeremy Stein, Jean Tirole, Michael Song, Vasiliki Skreta, and Pietro Veronesi and numerous seminar and conference audiences for comments. Section 5.4 of this draft subsumes results from our earlier paper titled "Information aggregation, investment and managerial incentives" (Albagli, Hellwig and Tsyvinski, 2011a). Hellwig gratefully acknowledges financial support from the European Research Council (starting grant agreement 263790). The views expressed herein are those of the authors and do not necessarily reflect the views of the National Bureau of Economic Research.

At least one co-author has disclosed a financial relationship of potential relevance for this research. Further information is available online at http://www.nber.org/papers/w23419.ack

NBER working papers are circulated for discussion and comment purposes. They have not been peer-reviewed or been subject to the review by the NBER Board of Directors that accompanies official NBER publications.

(C) 2017 by Elias Albagli, Christian Hellwig, and Aleh Tsyvinski. All rights reserved. Short sections of text, not to exceed two paragraphs, may be quoted without explicit permission provided that full credit, including $\odot$ notice, is given to the source. 
Imperfect Financial Markets and Shareholder Incentives in Partial and General Equilibrium Elias Albagli, Christian Hellwig, and Aleh Tsyvinski

NBER Working Paper No. 23419

May 2017

JEL No. D21,E22,G1,G18

\begin{abstract}
We analyze the firm-level and aggregate consequences of equity market imperfections in the form of noisy information aggregation for corporate risk-taking and investment. Market imperfections cause controlling shareholders to invest too much in upside risks and too little in downside risks in an attempt to capture market rents. In partial equilibrium, these inefficiencies are particularly severe if upside risks are coupled with near constant returns to scale. In general equilibrium, the shareholders' collective attempts to boost shareholder value of individual firms leads to a novel pecuniary externality that amplifies investment distortions with downside risks but offsets distortions with upside risks, thereby overturning the results from the partial equilibrium analysis. We consider policy interventions to correct the distortions, and show that in general equilibrium such interventions disrupt the financial market's allocational role. We analyze extensions of our model to excess leverage, agency conflicts between shareholders and managers, negative welfare effects of transparency, excess sensitivity of investment to stock prices, and dynamically inconsistent firm behavior.
\end{abstract}

Elias Albagli

Central Bank of Chile

Research Department

ealbagli@gmail.com

Christian Hellwig

Toulouse School of Economics

Manufacture de Tabacs,

21 Allées de Brienne,

31000 Toulouse

christian.hellwig@tse-fr.eu
Aleh Tsyvinski

Department of Economics

Yale University

Box 208268

New Haven, CT 06520-8268

and NBER

a.tsyvinski@yale.edu 


\section{Introduction}

Over the last 30 years, shareholder value maximization has been the guiding principle for decisionmaking in shareholder-owned companies. In a context of efficient financial markets, share prices fully internalize the value of a firm's activities. In the absence of externalities or market power, maximizing shareholder value thus results in rational, time-consistent planning by firms and socially efficient risk-taking and investment without any need for monitoring or regulation. In the aggregate, efficient markets then channel financial resources to their most productive uses with no need to interfere with market allocations. A strong case for laissez-faire emerges, as policy interventions are at best inconsequential, and at worst harmful to economic activity.

In practice, financial markets and firms are not quite as rational and efficient as their model counterparts. Arbitrage is a risky and costly activity. Equity prices and returns feature anomalies that seem difficult to reconcile with fundamental values. Firm decisions are often dictated more by internal and external conflicts of interest or short-term biases than by the adherence to a timeconsistent optimal plan. And imperfections in financial markets and seemingly irrational investment behavior can have important aggregate consequences.

In this paper, we analyze the consequences of financial market imperfections for corporate risktaking and investment. We argue that equity market imperfections cause shareholders to distort investment decisions in an attempt to capture market rents. Their rational response to market imperfections results in firm-level and aggregate outcomes that are socially inefficient and that contradict the view of the firm as a rational, time-consistent planner. We show that even small market imperfections can have severe consequence for investment and aggregate welfare. Our results suggest a new rationale for regulating financial risk-taking by firms that applies even without the standard justification of externalities or market power.

In sections 2 and 3, we develop a partial equilibrium model of a single firm whose incumbent shareholders make an investment decision prior to selling a fraction of their shares in a financial market populated by informed and noise traders. The share price then emerges as a noisy signal aggregating dispersed investor information about the firm's value.

In our model, the market-clearing share price must partially absorb shocks to demand and supply of securities, since informed traders are not willing or able to perfectly arbitrage perceived gaps between prices and expected fundamental values. This amplifies price fluctuations relative to the information about dividends that is aggregated through the market. The share price is therefore not just a noisy but also a biased estimate of the firm's dividends. 
This bias has two important properties: (i) it inherits any asymmetries in underlying cash flow risks, and (ii) it scales with the firm's initial investment decision. Together these two properties result in an endogenous rent-seeking motive for shareholders that distorts investment decisions.

Property (i) implies that expected share prices are generally not an unbiased estimate of expected dividends: if cash flow risks are concentrated on the upside, the excess price fluctuations are primarily on the upside and lead to an upwards bias in average share prices relative to expected dividends. If instead the cash flow risk is concentrated on the downside, the downside price fluctuations dominate, resulting in a downwards bias of expected share prices. This wedge between the expected market value and the expected dividend value of a firm's equity is a transfer from final to initial shareholders (or vice versa), in other terms, a rent accruing to incumbent shareholders.

Property (ii) then implies that incumbent shareholders can influence the magnitude of this rent through their investment decision. As our main result in this section, we show that rent-seeking incentives and investment distortions depend on two characteristics: risk asymmetries and returns to scale of investments. Firms with upside risks over-invest, while firms with downside risk underinvest. The returns to scale determine how flexibly a firm can adjust its investment to the gap between expected fundamentals and market returns. With near constant returns, the surplus from investing is small, but the scope for rent-seeking is particularly large. If near constant returns are coupled with upside risk, even small market frictions can induce incumbent shareholders to take excessively large risks purely to capture rents from selling their shares, while the firm in fact generates negative expected surplus. With downside risks, there can be severe under-investment, but surplus always remains positive.

These investment distortions offer a new rationale for corrective policy interventions. We characterize how regulatory oversight, transaction taxes or direct market interventions can restore efficiency either by directly controlling firm decisions or indirectly by altering the incumbent shareholder's perception of upside risk. The optimal intervention policy has the property of leaning against return asymmetries as a counterweight to the market imperfections.

In section 4, we embed the single-firm, partial equilibrium model in an aggregate model with a continuum of heterogeneous firms, each subject to idiosyncratic investment risk. The general equilibrium formulation achieves several objectives.

First, we provide a micro-foundation for expected or aggregate dividends as our main welfare criterion. The model adds an intertemporal substitution margin for representative incumbent and final shareholders which as we show aligns their aggregate valuations while still allowing for firmlevel mispricing. Any increase in aggregate dividends is then passed onto incumbent shareholders 
through the aggregate value of equity shares.

Second, as our main result in this section, we show that equity market imperfections lead to a new pecuniary externality which amplifies investment distortions in the case of downside risk, but mitigates them in the case of upside risk. The conclusions drawn from our general equilibrium model are thus the exact opposite of the partial equilibrium results.

The interaction between aggregate share prices and firm-level investment operates through two channels. First, when individual equity prices are subject to market frictions but the aggregate value of equity is determined from shareholders' intertemporal marginal rates of substitution, shareholders in any given firm do not internalize that by collectively distorting investment to boost their own share prices, they end up with lower aggregate dividends, lower aggregate market values of equity shares and lower welfare. Second, the market imperfection drives a wedge between the shareholders' aggregate intertemporal marginal rate of substitution, and the rate of return at which shareholders in an individual firm discount future dividends, which in turn influences the weight incumbent shareholders assign to maximizing future dividends vs. inflating current share prices. With downside risk, this wedge reinforces the shareholders' desire to inflate share prices, which amplifies under-investment and welfare losses. With upside risk, it instead reduces the shareholders' desire to inflate market prices, which limits overinvestment and partially restores efficiency. This explains the striking contrast between partial and general equilibrium results. ${ }^{1}$

Third, we show how policy interventions generate a tradeoff between the role of equity markets for firm-level incentives and intertemporal trade: policies that improve investment incentives perturb or disrupt the allocational role of stock markets. This tradeoff is particularly severe in the case of downside risk and near constant returns to scale, where any policy intervention that improves investment incentives either causes equity markets to completely shut down, or leads to significant intertemporal distortions and excess demand for shares caused by implicit subsidies to final shareholders. In the case of upside risk, regulatory interventions curb over-investment without disrupting intertemporal trade through equity markets.

In section 5, we discuss several extensions of our baseline model to illustrate how equity market imperfections influence shareholder incentives. Two recurring themes emerge. First, policies that are beneficial for shareholders and society when markets are efficient now risk being mis-used

\footnotetext{
${ }^{1}$ We think of the contrast between partial and general equilibrium results as follows: The partial equilibrium results suggest that in a given cross-section of firms with heterogeneous risk characteristics and investment returns, firms that are characterized by upside risk are most likely to engage in rent-seeking behavior. The general equilibrium results suggest that aggregate investment distortions are likely to be most severe in times when most firms are exposed to significant downside risks.
} 
for rent-seeking by shareholders, and may thus be socially harmful, though still advantageous to incumbent shareholders. Second, rent-seeking incentives by incumbent shareholders lead to conflicts of interest between successive or concurrent shareholder generations and result in departures from the view of shareholder value maximization as an optimal, time-consistent plan.

First, we add external borrowing with costly state verification (Townsend, 1979; Gale and Hellwig, 1985) to our model of investment. We show that incumbent shareholders seek to take on excessive leverage, as this tilts the distribution of equity returns towards the upside, inflating the market value of equity shares, and at the same time allows them to scale up the investment to increase shareholder rents. If informational frictions are sufficiently important, shareholders may even borrow to invest in projects with negative expected returns, just to gain from the distortion in equity prices. Equity market imperfections thus dilute the discipline imposed by credit spreads.

Next, we argue that our analysis is robust to the inclusion of agency conflicts between shareholders and managers. Rent-seeking by incumbent shareholders is caused by market imperfections and hence not affected by agency conflicts inside the firm. Shareholder discretion to design CEO incentives instead facilitates rent-seeking, and contracts such as stock options that serve to provide optimal risk-taking incentives in efficient markets now serve to extract shareholder rents. Restrictions on executive compensation contracts then offer an additional margin for welfare-improving policy interventions. In some cases, agency costs may even have social value if they reduce the shareholders' ability to extract rents.

Third, we show that public information about the firms' investment returns may be socially harmful, when rent-seeking motives are sufficiently severe. While better public information is always desirable in efficient markets, here it enables the incumbent shareholders to fine-tune their rent-seeking activities. This result mirrors Morris and Shin's (2002) finding on the social value of public information in beauty contest games, but is based on a different model in which inefficiency results from rent-seeking incentives that are based on financial market imperfections.

Fourth, we show that information feedback from stock prices to investment decisions leads to excess sensitivity of investment to share prices and a negative co-movement of investment with future returns. Information feedback causes shareholders to cater to market expectations of returns. Depending on the realization of fundamentals and liquidity shocks, markets can be overly optimistic or pessimistic about the firm's return prospects, resulting in excessive investment when share prices are high, and foregone opportunities when share prices are low. Polk and Sapienza (2009) offer direct empirical support for these model predictions.

Fifth, we allow for sequential decisions by successive shareholder generations and show that 
market imperfections and shareholder rent-seeking lead to dynamically inconsistent, Pareto-inferior firm decisions. When interpreting the firm as a unitary decision-maker, its behavior can no longer be rationalized as the outcome of a time-consistent optimal plan, but instead display clear symptoms of bounded rationality: if our static investment model has similarities to a consumer problem with limited self-control (e.g. Gul and Pesendorfer, 2001), our dynamic model shows how rent-seeking by incumbent shareholders leads to endogenous preference reversals, time-inconsistency, and lack of commitment in firm behavior (e.g. Gul and Pesendorfer, 2005). Our model thus offers a foundation - based on financial market imperfections rather than psychological factors - of behavioral biases in corporate decision-making. Similar conflicts of interest arise between concurrent shareholders with different investment horizons and differential access to information.

Related Literature. Our paper builds on ideas from several distinct fields. To our knowledge, they have not been brought together within a single unified framework.

The stylized facts (see second paragraph) that motivate our analysis are well documented: Pontiff (1996), D’Avolio (2002) and Wurgler and Zhuravskaya (2002) among others provide evidence on the costs and risks of arbitrage. Schwert (2003) and Nagel (2013) survey asset pricing anomalies such as cross-sectional predictability (such as size or value premium) or time-series predictability (i.e. momentum, reversals, announcement effects), including evidence linking returns to skewness, belief dispersion and investor sentiment. Tirole (2006) surveys the corporate finance literature that documents and analyzes conflicts of interest associated with delegation of decisions to managers. Becht, Bolton and Roell (2003) survey the corporate governance literature that emphasizes collective action problems and conflicts of interest among heterogeneous groups of shareholders with diverging objectives. Baker and Wurgler (2013) discuss the behavioral literature which analyzes how firm decisions may be influenced by investors' or managers' psychological biases. Finally, the 2007-2009 great recession offers ample prima facie evidence on the link between financial booms and busts, corporate risk-taking and investment, and aggregate activity and welfare.

Our model of the financial market builds on models of noisy information aggregation (Grossman and Stiglitz, 1980, Hellwig, 1980, Diamond and Verrecchia, 1981), or more specifically the formulation in Albagli, Hellwig and Tsyvinski (2011b) which characterizes returns for arbitrary securities in a non-linear noisy rational expectations equilibrium model and argues that such a model can account for cross-sectional asset pricing puzzles. ${ }^{2}$ We depart from Albagli, Hellwig and Tsyvinski

\footnotetext{
${ }^{2}$ The noisy information aggregation model, in particular our formulation in Albagli, Hellwig and Tsyvinski (2011b), is similar to common value auctions following Milgrom (1981). Our discussion of market value versus dividends mirrors the comparison between efficiency and revenue maximization in auction theory. However, auction theory
} 
(2011b) in two important aspects. First, we endogenize security cash flows as the outcome of firm decisions. Second, we embed the firms in a general equilibrium environment. Endogenizing investment and cash flows is challenging even in partial equilibrium because of the interaction between how information aggregation affects investment incentives, and how investment in turn feeds into asset prices, payoffs and information aggregation. These challenges are compounded by the general equilibrium feedback from aggregate share prices to firm level incentives.

More generally, the market micro structure literature explores the effects of frictions in price formation for given security payoffs (see, e.g. Biais, Glosten and Spatt, 2005). We propose a parsimonious model to analyze how such micro structure frictions influence not just asset prices but also firm behavior and aggregate outcomes. Existing models often rely on functional form or distributional assumptions that limit the scope for analyzing such feedbacks.

Our treatment of general equilibrium effects relates to the growing literature on pecuniary externalities. In our model, a pecuniary externality results from market imperfections, when individual and aggregate share prices directly enter incumbent shareholder preferences. This is different from the pecuniary externalities commonly identified in the literature on financial constraints, where share prices indirectly affect investment incentives by relaxing or tightening collateral constraints (Lorenzoni 2008) or incentive constraints (Farhi, Golosov, Tsyvinski 2009). ${ }^{3}$ With downside risk, our pecuniary externality has the potential to generate significantly larger aggregate distortions because (i) it affects all firms, rather than a subset of financially constrained firms, and (ii) rather than being the primary source of inefficiency, it amplifies distortions caused by market imperfections. The interaction of trading frictions with pecuniary externalities also appears in Asriyan (2016), but in a context where frictions in debt markets amplify balance sheet effects.

Holmstrom and Tirole (1993) emphasize the social value of tying managerial incentives to market prices to resolve agency conflicts, under the background hypothesis that financial markets are efficient. Our analysis instead suggests that market-based incentives may do more harm than good when there are market imperfections. This is similar to Bolton, Scheinkman, and Xiong (2006), who argue that shareholders may want to distort investments in order to boost short-term share prices that contain a speculative component due to heterogeneous priors. By modeling market imperfections and shareholder rent-seeking parsimoniously through noisy information aggregation, we can fully develop the positive and normative implications of this premise. ${ }^{4}$

\footnotetext{
takes securities as given to focus on market design, while we take the market as given and endogenize asset returns.

${ }^{3}$ See also Greenwald and Stiglitz (1986), Geanakoplos and Polemarchakis (1986), and Dávila and Korinek (forthcoming), among many other papers.

${ }^{4}$ In Stein $(1988,1989)$ and Benmelech, Kandel and Veronesi (2010), market-based incentives exacerbate agency
} 
Our model of shareholder incentives is related to market-timing or catering theories which discuss how firm behavior responds to market anomalies (Stein, 1996; Baker and Wurgler, 2013). However there are some important distinctions. First, whereas existing catering theories analyze firm incentives and behavior when faced with some exogenously given form of "market irrationality", we offer a parsimonious microfoundation for such behavior by endogenizing - via noisy information aggregation - the origins of departures from market efficiency. These micro-foundations impose structure on the relation between equity prices and firm behavior that can emerge and therefore enrich the testable implications of our model. Second, by embedding firm-level distortions in a general equilibrium model, we can analyze to what extent catering or rent-seeking incentives have harmful aggregate effects, and how they can be regulated through policy interventions. Third, throughout most of our analysis, investment decisions are taken prior to equity trading, and therefore incumbent shareholders cater to expected, not realized market outcomes. Catering to current market sentiment arises only in section 5.4, where we allow for information feedback from equity prices to investment.

Finally, the behavioral corporate finance literature argues that firm decisions may be influenced by investors' or managers' psychological biases (Baker and Wurgler, 2013). Our model reinterprets such behavior as the rational response by controlling shareholders to underlying market imperfections. In particular, we highlight the link between catering incentives and corporate short-termism or lack of time consistency (see Derrien et al. 2013 for direct evidence on this link).

\section{Baseline model: partial equilibrium}

Our model has three stages. In the first stage, incumbent shareholders in a firm decide on an observable investment decision $k \geq 0$. In the second stage, they sell a fraction $\alpha \in(0,1]$ of the shares to outside investors. At the final stage, the firm's cash flow $\Pi(\theta, k) \equiv R(\theta) k-C(k)$ is a function of the investment $k$ and a stochastic fundamental $\theta \in \mathbb{R}$, and paid to the final shareholders. The fundamental $\theta$ is distributed according to $\theta \sim \mathcal{N}\left(0, \lambda^{-1}\right)$. The return $R(\cdot)$ on the investment is a positive, increasing function of the firm's fundamental, $C(k)=k^{1+\chi} /(1+\chi)$ denotes the cost of investment, and $\chi$ the firm's returns to scale.

Throughout the paper, we equate efficiency and welfare to the maximization of expected dividends $\mathbb{E}(\Pi(\theta, k))$, and ask whether market prices align shareholder incentives with this measure

conflicts between shareholders and managers, when the latter can manipulate the information contained in stock prices but not systematically fool shareholders. Our analysis instead emphasizes the role of shareholder incentives rather than agency conflicts and information manipulation. 
of aggregate welfare. The ex ante efficient investment $k^{*}$ maximizes $\mathbb{E}(\Pi(\theta, k))$. Our general equilibrium model in section 4 provides microfoundations for this welfare criterion in an economy with a continuum of heterogeneous firms and representative sets of incumbent and final shareholders.

\subsection{Stage 2: Description of the Market Environment.}

There are two types of outside investors: a unit measure of risk-neutral informed traders, who are indexed by $i$, and noise traders.

Informed traders observe a private signal $x_{i} \sim \mathcal{N}\left(\theta, \beta^{-1}\right.$ ), which is i.i.d. across traders (conditional on $\theta$ ). After observing $x_{i}$, an informed trader submits a price-contingent demand schedule $d_{i}(\cdot): \mathbb{R} \rightarrow[0, \alpha]$, to maximize expected wealth $w_{i}=d_{i} \cdot(\Pi(\theta, k)-P)$. That is, informed traders cannot short-sell, and can buy at most $\alpha$ units of the shares. An informed trader's strategy is then a function $d\left(x_{i}, P\right) \in[0, \alpha]$ of the private signal and the price.

Noise traders place an order to purchase a random quantity $\alpha \Phi(u)$ of shares, where $u \sim$ $\mathcal{N}\left(0, \delta^{-1}\right)$ is independent of $\theta$, and $\delta^{-1}$ is a measure of demand noise.

The aggregate demand for shares is $D(\theta, P)=\int d(x, P) d \Phi(\sqrt{\beta}(x-\theta))+\alpha \Phi(u)$, where $\Phi(\sqrt{\beta}(x-$ $\theta$ )) represents the cross-sectional distribution of private signals $x_{i}$ conditional on $\theta$, and $\Phi(\cdot)$ denotes the cdf of a standard normal distribution. The orders submitted by informed and noise traders are executed at a market-clearing price $P$ such that $D(\theta, P)=\alpha$.

Let $H(\cdot \mid x, P)$ denote the traders' posterior cdf of $\theta$, conditional on observing a private signal $x$, and a market-clearing price $P$. A noisy Rational Expectations Equilibrium at stage 2 consists of a demand function $d(x, P)$, a price function $P(\theta, u ; k)$, and posterior beliefs $H(\cdot \mid x, P)$, such that $d(x, P)$ is optimal given the shareholder's beliefs $H(\cdot \mid x, P) ; P(\theta, u ; k)$ clears the market for all $(\theta, u)$ and $k$; and $H(\cdot \mid x, P)$ satisfies Bayes' Rule whenever applicable.

\subsection{Stage 2: Equilibrium Characterization.}

For a given $k$, our first result characterizes the equilibrium share price in the unique noisy Rational Expectations Equilibrium, in which demand schedules are non-increasing in $P$. Monotonicity restrictions arise naturally if trading takes place through limit orders.

\section{Proposition 1 Equilibrium Characterization and Uniqueness}

Define $z \equiv \theta+1 / \sqrt{\beta} \cdot u$. In the unique equilibrium in which the informed traders' demand $d(x, P)$ is non-increasing in $P$, the market-clearing price function is

$$
P(z, k)=\mathbb{E}(\Pi(\theta, k) \mid x=z, z) .
$$


The variable $z$ is a sufficient statistic for the information conveyed through the share price. Conditional on $\theta, z$ is distributed according to $z \sim \mathcal{N}\left(\theta,(\beta \delta)^{-1}\right)$, while its unconditional distribution is $z \sim \mathcal{N}\left(0, \lambda_{z}^{-1}\right)$, where $\lambda_{z}^{-1}=\lambda^{-1}+(\beta \delta)^{-1}$. The characterization of $P(z, k)$ gains its significance from the comparison with the share's expected dividend value $V(z, k) \equiv \mathbb{E}(\Pi(\theta, k) \mid z)$.

The equilibrium share price differs systematically from the expected dividend value: Both are characterized as expected dividends conditional on the information contained in $z$. However, the share price treats the signal $z$ as if it had precision $\beta+\beta \delta$ (equal to the sum of the private and the price signal precision), when in reality its precision is only equal to $\beta \delta$. Hence, the market price is based on an expectation of the marginal return to the investment level $k$ that conditions places a higher weight on the market signal $z$, relative to its objective information content. Therefore, when $z$ conveys sufficiently positive news about fundamentals, the price is upwards-biased, while if $z$ conveys sufficiently negative news the price is biased downwards.

The overweighting of the market signal in the price is fully consistent with Bayesian updating based on private and public information. In the equilibrium representation, the sufficient statistic $z$ represents the private signal of the trader who must be just indifferent between buying or not buying the stock if the market clears, which summarizes the demand for equity shares through noise traders $(u)$ and informed traders $(\theta)$. The identity of this trader shifts in a systematic way with demand conditions: if informed traders become on average more optimistic (higher $\theta$ ) or noise trader demand increases (higher $u$ ), the marginal informed traders' private signal must also increase to keep the market in equilibrium. To keep this marginal trader indifferent, the market price must increase with $z$ and reveal $z$ publicly to all market participants or outside observers. The expression for $P(z, k)$ compounds this second informational effect of $z$ with the market-clearing effect, whereas the expected dividend $V(z, k)$ only contains the informational response to $z .^{5}$

\subsection{Stage 1: Investment Decision}

At the first stage, incumbent shareholders choose $k$ to maximize the expected value of their equity:

$$
\max _{k \geq 0} \mathbb{E}\{\alpha P(z ; k)+(1-\alpha) \Pi(\theta, k)\},
$$

where $P(z ; k)$ is characterized by $(1)$. The incumbent shareholder's objective differs from expected dividends by the term $\alpha \mathbb{E}(P(z ; k)-\Pi(\theta, k))$, which can be interpreted as a pure transfer, i.e. a

\footnotetext{
${ }^{5}$ We extensively discussed properties of this wedge between $P(z, k)$ and $V(z, k)$ in Albagli, Hellwig and Tsyvinski (2011b). The closed form characterization extends to a general model with risk-neutral traders and arbitrary distributions and position limits. The functional form assumptions are convenient for comparative statics, but not otherwise crucial for our analysis.
} 
rent that acrues to incumbent shareholders. Incumbent shareholders can influence the expected size of this transfer through the choice of $k$. Noisy information aggregation thus introduces a rent-seeking motive into incumbent shareholder preferences.

This rent-seeking motive arises because incumbent shareholders sell a fraction of their equity share at a price that differs in expectation from the shares' expected dividends. In the limit where the incumbent shareholders keep all their shares (i.e. $\alpha \rightarrow 0$ ), or in an efficient market (i.e. if $P(z ; k)=V(z ; k))$, the rent-seeking motive disappears, and incumbent and final shareholder incentives are aligned on maximizing $\mathbb{E}(\Pi(\theta, k)){ }^{6}$

Two properties of noisy information aggregation are key for generating a rent-seeking motive and conflict of interest between incumbent and final shareholders. First, noisy information aggregation adds not just noise to stock prices, which would average out from an ex ante perspective, but also a bias. In other words, $P(z ; k)-V(z ; k)$ responds systematically to the price realization (i.e. $\Pi-P$ and $P$ are not orthogonal to each other). Second, incumbent shareholders have the means to influence the magnitude of this wedge through the investment decision taken at the first stage.

\section{Investment distortions from market frictions}

In this section, we explore investment distortions due to noisy information aggregation in partial equilibrium, and discuss possible policy interventions designed to restore efficiency.

\subsection{Equilibrium investment distortions}

In our model, the efficient investment $k^{*}$ sets $C^{\prime}\left(k^{*}\right)=\mathbb{E}(R(\theta))$. The initial shareholders instead choose $\hat{k}$ to equate the marginal cost of investment to a weighted average of expected market return $\mathbb{E}(\mathbb{E}(R(\theta) \mid x=z, z))$ and expected dividend return $\mathbb{E}(R(\theta))$ :

$$
C^{\prime}(\hat{k})=\alpha \mathbb{E}(\mathbb{E}(R(\theta) \mid x=z, z))+(1-\alpha) \mathbb{E}(R(\theta)) .
$$

It then follows that $\hat{k} \gtreqless k^{*}$ if and only if $\mathbb{E}(\mathbb{E}(R(\theta) \mid x=z, z)) \gtreqless \mathbb{E}(R(\theta))$. Whenever the expected market return to investment exceeds the expected fundamental return, the initial shareholders find it optimal to over-invest to enhance the over-valuation of their shares. When instead the expected wedge is negative, the initial shareholders want to under-invest in order to limit the

\footnotetext{
${ }^{6} P(z, k)=V(z, k)$ could result for example with free entry of uninformed arbitrageurs as in Kyle (1985), or when there is a public signal $z$, but no private information, and no heterogeneity among informed traders, so that they must be indifferent about buying at equilibrium. This also corresponds to the limiting case of our model with $\beta \rightarrow 0$.
} 
under-valuation of their shares. The return ratio $\mathbb{E}(\mathbb{E}(R(\theta) \mid x=z, z)) / \mathbb{E}(R(\theta))$ determines the impact of market frictions on expected investment returns.

We first relate the return ratio and hence the sign of the investment distortion to asymmetry between upside and downside risks. A return $R(\cdot)$ is symmetric if $R(\theta)-R(0)=R(0)-R(-\theta)$ for all $\theta>0 . \quad R(\cdot)$ is dominated by upside risk, if $R(\theta)-R(0) \geq R(0)-R(-\theta)$ for all $\theta>0$, and dominated by downside risk if $R(\theta)-R(0) \leq R(0)-R(-\theta)$ for all $\theta>0$. This classification compares gains and losses at fixed distances from the prior median to determine whether risks are concentrated on the upside or on the downside.

Standard arguments of compounding normal distributions imply that $\mathbb{E}(\mathbb{E}(R(\theta) \mid x=z, z))=$ $\int_{-\infty}^{\infty} R(\theta) d \Phi\left(\sqrt{\lambda_{P}} \theta\right)$, for some $\lambda_{P}^{-1}>\lambda^{-1}$, i.e. from an ex ante perspective the market attributes too much weight to tail realizations of $\theta$. The parameter $\lambda_{P}^{-1}$ depends on $\beta, \delta$, and $\lambda$ and summarizes the severity of market frictions. By Theorem 2 in Albagli, Hellwig and Tsyvinski (2011b), if $R(\cdot)$ is symmetric, $\mathbb{E}(\mathbb{E}(R(\theta) \mid x=z, z))=\mathbb{E}(R(\theta))$ and investment is undistorted $\left(\hat{k}=k^{*}\right)$. If $R(\cdot)$ is dominated by upside risk then $\mathbb{E}(\mathbb{E}(R(\theta) \mid x=z, z))>\mathbb{E}(R(\theta))$ and the firm over-invests $\left(\hat{k}>k^{*}\right)$. If $R(\cdot)$ is dominated by downside risk then $\mathbb{E}(\mathbb{E}(R(\theta) \mid x=z, z))<\mathbb{E}(R(\theta))$ and the firm underinvests $\left(\hat{k}<k^{*}\right) .^{7}$

When returns to investment are asymmetrically distributed, the bias in share prices that is due to the over-weighting of the market signal $z$ results in upside bias (in the case of upside risk) or downside bias (in the case of downside risk) of the expected market return to investment. Shares are over-priced in expectation when $z$ is high and under-priced when $z$ is low, and the extent of overor under-pricing depends on the conditional uncertainty about dividends, given $z$. With symmetric returns, posterior uncertainty is symmetric w.r.t. the realization of $z$ and over- and under-pricing just offset each other. But in the case of upside (downside) risk, this uncertainty is higher (lower) on the upside so that on average the market over-values (under-values) investment returns.

We next relate the magnitude of investment distortions and efficiency losses to the return ratio $\mathbb{E}(\mathbb{E}(R(\theta) \mid x=z, z)) / \mathbb{E}(R(\theta))$, the elasticity of marginal costs $\chi$, and the fraction of shares sold $\alpha$. Investment distortions are defined as $\left|\hat{k} / k^{*}-1\right|$. The efficiency loss $\Delta=1-V / V^{*}$ is the loss in expected dividends $V=\mathbb{E}(R(\theta)) \cdot \hat{k}-C(\hat{k})$, relative to the efficient level $V^{*}=\mathbb{E}(R(\theta)) \cdot k^{*}-C\left(k^{*}\right)$. If $\Delta>1$, efficiency losses are so large that expected dividends are negative.

\section{Proposition 2 : Comparative statics of investment distortions and efficiency losses.}

\footnotetext{
${ }^{7}$ Furthermore, for upside risks, the return ratio $\mathbb{E}(\mathbb{E}(R(\theta) \mid x=z, z)) / \mathbb{E}(R(\theta))$ is strictly increasing in $\lambda_{P}^{-1}$, while for downside risks the return ratio is strictly decreasing in $\lambda_{P}^{-1}$.
} 
Figure 1: Investment distortions and efficiency losses
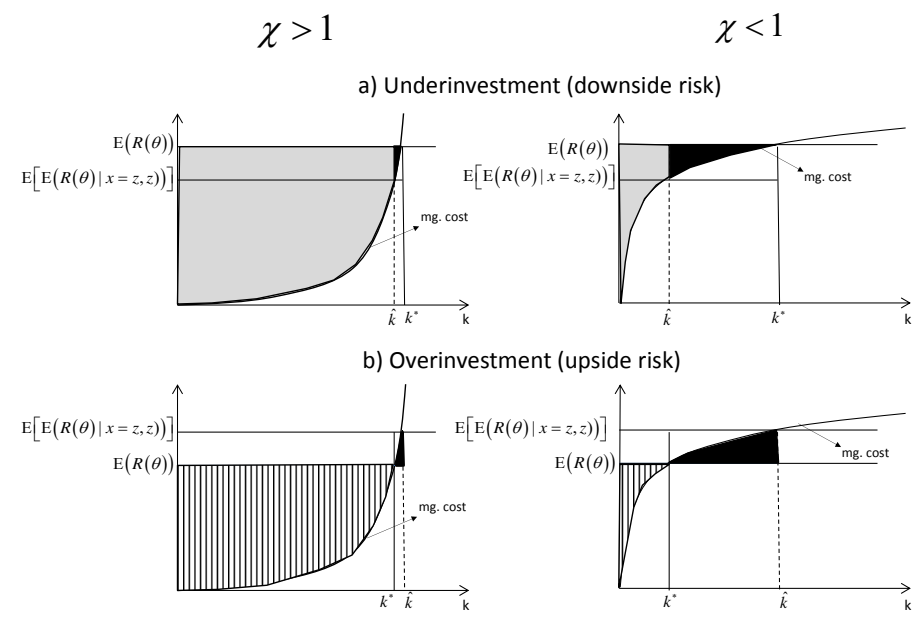

(i) Comparative Statics: $\left|\hat{k} / k^{*}-1\right|=\Delta=0$ only if $\mathbb{E}(\mathbb{E}(R(\theta) \mid x=z, z))=\mathbb{E}(R(\theta))$, $\chi \rightarrow \infty$, or $\alpha \rightarrow 0$. $\left|\hat{k} / k^{*}-1\right|$ and $\Delta$ are increasing in $\alpha$ and $|\mathbb{E}(\mathbb{E}(R(\theta) \mid x=z, z)) / \mathbb{E}(R(\theta))-1|$ and decreasing in $\chi$.

(ii) Bounded Distortions on the Downside: If $\mathbb{E}(\mathbb{E}(R(\theta) \mid x=z, z))<\mathbb{E}(R(\theta))$, then $\lim _{\chi \rightarrow 0} \hat{k} / k^{*}=0$ and $\lim _{\chi \rightarrow 0} \Delta=1$.

(iii) Unbounded Distortions on the Upside: $\left|\hat{k} / k^{*}-1\right|$ and $\Delta$ become infinitely large, if either $\mathbb{E}(\mathbb{E}(R(\theta) \mid x=z, z)) / \mathbb{E}(R(\theta)) \rightarrow \infty$, or $\chi \rightarrow 0$ and $\mathbb{E}(\mathbb{E}(R(\theta) \mid x=z, z))>\mathbb{E}(R(\theta))$.

(iv) Negative Expected Dividends: Expected dividends are negative $(\Delta>1)$, whenever

$$
\alpha\left(\frac{\mathbb{E}(\mathbb{E}(R(\theta) \mid x=z, z))}{\mathbb{E}(R(\theta))}-1\right)>\chi
$$

The return ratio determines the initial shareholders' incentive to distort their investment, while the returns to scale parameter $\chi$ determines their ability to do so. With close to constant returns (low $\chi$ ), optimal investment is easily scaleable and thus very sensitive to expected market returns, and the scope for investment distortions and efficiency losses can become very large. At the other extreme, if marginal costs are very sensitive to $k$ (high $\chi$ ), investment is not easily scaleable, and investment distortions and welfare losses are small.

Figure 1 illustrates the comparative statics described by proposition 2. We plot marginal costs and expected market and fundamental returns, for high and low values of $\chi$, and for the case with over- and under-investment respectively. In all cases, the black triangular area corresponds to the 
welfare loss, relative to the efficient investment level $k^{*}$. The upper panels consider the case with under-investment: the grey area corresponds to the realized social surplus $V$, while the maximal surplus $V^{*}$ corresponds to the combined gray and black areas. The lower two panels consider the case with over-investment: the striped area corresponds to $V^{*}$, the welfare loss corresponds to the black area, and the realized surplus $V$ to the difference between the striped and the black areas. In both cases, a lower value of $\chi$ leads to a larger impact of frictions on investment and welfare.

In extreme cases, welfare losses exceed $100 \%$ of the first-best welfare level, i.e. the firm generates negative expected cash flows. This occurs, whenever the elasticity of marginal costs $\chi$ is less than the return distortion, which is given by the distance of the return ratio from 1 , multiplied by the fraction of shares sold. Even a small departure from the efficient markets benchmark (in terms of $\mathbb{E}(\mathbb{E}(R(\theta) \mid x=z, z)) / \mathbb{E}(R(\theta)))$ can have very large efficiency consequences for firms that operate near constant returns, and with investments that are characterized by upside risk. On the other hand, with under-investment the firm's expected dividends always remain positive. ${ }^{8}$

To summarize, frictions in equity markets can distort shareholder incentives to invest and take risks. The direction and magnitude of the resulting investment distortions and efficiency losses depend on the firms' returns to scale and on whether returns are characterized by upside or downside risks. If near constant returns are coupled with upside risks, even small frictions in financial markets can have very large efficiency consequences - so large in fact that the firm generates negative expected surplus.

\subsection{Policy interventions}

Our model offers a new rationale for corrective policy measures that offset the distortive effects of equity market frictions on risk-taking incentives. If financial markets were efficient, such interventions could only reduce welfare.

Direct Regulatory Oversight: Investment Caps or Floors. A simple way to regulate the firm's incentives is to restrict shareholder discretion by introducing a cap on investment to eliminate over-investment or a floor to eliminate under-investment. The optimal regulation imposes a cap or floor equal to $k^{*}$.

Financial Transaction Tax. Taxes on financial transactions or dividends can also be used to

\footnotetext{
${ }^{8}$ Further distortions emerge if the firm can choose between different return profiles. While a social planner wants the firm to maximize the fundamental return $\mathbb{E}(R(\theta))$, the initial shareholders have a preference for maximizing expected market returns $\mathbb{E}(\mathbb{E}(R(\theta) \mid x=z, z))$. This skews decisions in favor of upside risks.
} 
influence firm incentives. But such taxes must be state-contingent in order to be effective. ${ }^{9}$ Consider a contingent transaction $\operatorname{tax} \tau(z)$ that conditions on the market price. Such a tax modifies the incumbent shareholder's objective function to $\alpha \mathbb{E}((1-\tau(z)) P(z, k))+(1-\alpha) \mathbb{E}(\Pi(\theta, k))$. The tax function $\tau(z)$ implements $k^{*}$ if and only if $\mathbb{E}\left\{(1-\tau(z)) P_{k}\left(z, k^{*}\right)\right\}=0$.

Proposition 3 Contingent transaction taxes must lean against return asymmetries.

For any $\tau(z)$, let $\hat{\tau}(z)=(\tau(z)-\mathbb{E}(\tau(z))) /(1-\mathbb{E}(\tau(z)))$. A tax policy $\tau(\cdot)$ implements $k^{*}$, if and only if

$$
\mathbb{E}(\mathbb{E}(R(\theta) \mid x=z, z))-\mathbb{E}(R(\theta))=\operatorname{cov}(\hat{\tau}(z), E(R(\theta) \mid x=z, z)) .
$$

The optimal tax policy reduces the asymmetry in shareholders' investment returns: If the tax function is increasing, then returns are taxed more heavily on the upside. The shareholders' returns are then less dominated by upside risk, which dampens investment incentives. This reduces distortions if the gross investment returns were dominated by upside risk. If instead the tax function is decreasing, then it shifts the shareholder's expected returns to the upside, which strengthens investment incentives. This policy improves efficiency when returns are dominated by downside risk. Equation (5) spells out how the tax policy on the RHS alters expected shareholder returns until the change in shareholder returns corresponds to the level needed to implement $k^{*}$ (on the LHS). Taxes and tax revenues do not have to be strictly positive on average, since incentives are shifted by the relative size of taxes on the upside vs. the downside.

Market Interventions. Market interventions are another channel through which a policy maker can influence investment incentives. Like the optimal tax policy, they are based on the idea of "leaning against return asymmetries".

Suppose that a policy maker commits to buy shares at a guaranteed support price $\bar{P}>0$. For a given $k$, and for any $z$ such that $P(z, k) \equiv \mathbb{E}(R(\theta) \mid x=z, z) k-C(k)>\bar{P}$, this intervention has no effect on the market. However, if $P(z, k)<\bar{P}$, the policy maker buys a positive level of shares. This occurs whenever $z$ falls below some threshold $\hat{z}$. The initial shareholders' objective is then to maximize $\alpha \mathbb{E}(\max \{\bar{P}, P(z, k)\})+(1-\alpha) \mathbb{E}(\Pi(\theta, k))$. The implemented investment $\hat{k}$ satisfies the following first order condition:

$$
C^{\prime}(\hat{k})=\frac{\alpha \int_{\hat{z}}^{\infty} \mathbb{E}(R(\theta) \mid x=z, z) d \Phi\left(\sqrt{\lambda_{z}} z\right)+(1-\alpha) \mathbb{E}(R(\theta))}{1-\alpha+\alpha\left(1-\Phi\left(\sqrt{\lambda_{z}} \hat{z}\right)\right)}
$$

\footnotetext{
${ }^{9}$ With an uncontingent tax on share sales, the shareholders maximize $\mathbb{E}((1-\tau) \alpha P(z ; k)+(1-\alpha) V(z, k))$, reducing the relative weight on the share price from $\alpha$ to $\alpha(1-\tau) /(1-\alpha \tau)$. This reduces the distortion, but the tax has to be completely confiscatory $(\tau=1)$ if it is to fully restore efficiency. Likewise, an uncontingent dividend tax is fully passed into share prices with no effect on incentives.
} 
This condition uniquely defines $\hat{k}$ as a function of $\hat{z}$, and the associated value of $\bar{P}$ then satisfies $\bar{P}=\mathbb{E}(R(\theta) \mid x=\hat{z}, \hat{z}) \hat{k}-C(\hat{k}) \cdot{ }^{10}$ This intervention increases investment and therefore improves efficiency only if the equilibrium without intervention resulted in under-investment. ${ }^{11}$

Proposition 4 When $\mathbb{E}(\mathbb{E}(R(\theta) \mid x=z, z))<\mathbb{E}(R(\theta))$, support prices improve efficiency.

(i) Define $z^{*}$ by $\mathbb{E}(R(\theta))=\mathbb{E}\left(\mathbb{E}(R(\theta) \mid x=z, z) \mid z \geq z^{*}\right)$. A market intervention with a support price $\bar{P}$ implements $k^{*}$, if and only if $\bar{P}=\mathbb{E}\left(R(\theta) \mid x=z^{*}, z^{*}\right) k^{*}-C\left(k^{*}\right)$.

(ii) Market interventions generate negative expected revenues.

With a support price, the expected market return from investment is $\mathbb{E}(\mathbb{E}(R(\theta) \mid x=z, z) \mid z \geq \hat{z})$. Just like the tax policy, the efficient market intervention aligns the expected market return with $\mathbb{E}(R(\theta))$ with a support price that equates the intervention threshold $\hat{z}$ to $z^{*}$.

However, such market interventions are not revenue-neutral. Although the policy maker buys shares at prices below fundamental values, he is also exposed to a winner's curse problem and will buy a larger share when fundamentals are worse. Because of the winner's curse problem, the policy maker's expected revenue is negative.

The focus on efficiency masks the fact that policy interventions have re-destributive effects. In partial equilibrium, there is a natural conflict of interest between incumbent shareholders and final shareholders over shareholder rents and policies that seek to curb rent-seeking incentives. Incumbent shareholders dislike policies that reduce the rents they can capture without a compensating subsidy, and favor policies that provide incentives through explicit or implicit subsidies. Final shareholders and the social planner benefit only if expected dividends increase by more than rents and subsidies going to initial shareholders. Thus direct regulatory interference that does not involve transfers or subsidies is clearly preferred by final shareholders but resisted by incumbent shareholder who would rather favor market interventions or direct subsidies.

\section{General equilibrium: micro-foundations, welfare and policy}

In this section, we achieve three objectives. First, we provide a rationale for equating welfare to expected dividends in the context of a general equilibrium economy with heterogeneous firms. We measure welfare from the perspective of representative incumbent and final shareholders who invest

\footnotetext{
${ }^{10}$ While $\bar{P}$ and $\hat{k}$ are uniquely determined for a threshold signal $\hat{z}$, the reverse need not be true: The relation between $\bar{P}$ and $\hat{z}$ is not necessary monotonic, resulting in the possibility of multiple equilibria for the investment level and market outcome, for a given price support $\bar{P}$.

${ }^{11}$ With over-investment, the policy maker would have to short-sell equity at a pre-set price to limit upside gains.
} 
in a broad cross-section of firms with firm-specific fundamentals, signals and noise-trading shocks, and no aggregate uncertainty. Second, we discuss how individual firms' investment decisions interact in general equilibrium and identify a novel pecuniary externality that amplifies partial equilibrium investment distortions with downside risk, but dampens them with upside risk, thus resulting in the opposite conclusions of the partial equilibrium model. Third, we describe the general equilibrium effects of policy interventions.

\subsection{Micro-Foundations}

There is a unit measure of firms, indexed by $i$ and characterized by a firm-specific fundamental $\theta_{i}$ which is iid across firms and distributed according to $\theta_{i} \sim \mathcal{N}\left(0, \lambda^{-1}\right)$. These firms are owned and controlled by incumbent shareholders who in a first stage control investment decisions $k_{i}$ by each of these firms. Afterwards, incumbent shareholders sell a fraction $\alpha$ of shares to a new generation of "final shareholders".

Our general equilibrium model combines three decision layers: the aggregate stock market endogenously determines $\alpha$ along with the aggregate market value of equity. The microstructure of equity markets determines individual firms' share prices. The incumbent shareholders' stage 1 decision determines investment in each firm. We describe each of these layers in turn.

1. Preferences and aggregate market values: Let $T=\int P_{i} d i$ denote the aggregate market value of firms, and $V=\int \Pi_{i} d i$ the aggregate dividends. The incumbent shareholders' preferences over stage 1 consumption $C_{1}^{I}=\alpha T$ and stage 2 consumption $C_{2}^{I}=(1-\alpha) V$ is $v_{I}\left(C_{1}^{I}\right)+u_{I}\left(C_{2}^{I}\right)$. The final shareholders' preferences over stage 1 consumption $C_{1}^{F}=-\alpha T$ and stage 2 consumption $C_{2}^{F}=\alpha V$ is $C_{1}^{F}+u_{F}\left(C_{2}^{F}\right)$, where the functions $u_{I}, v_{I}$ and $u_{F}$ satisfy standard Inada conditions. For a given value of $V, T$ and $\alpha$, the incumbent and final shareholders consumption levels satisfy

$C_{1}^{I}=\alpha T=-C_{1}^{F}, C_{2}^{I}=(1-\alpha) V$, and $C_{2}^{F}=\alpha V$, and the equilibrium values of $\alpha$ and $T$ are uniquely determined from the incumbent and final shareholders' first-order conditions

$$
\frac{T}{V}=\hat{Q}^{-1}=\frac{u_{I}^{\prime}((1-\alpha) V)}{v_{I}^{\prime}(\alpha T)}=u_{F}^{\prime}(\alpha V)
$$

Therefore, in the aggregate the financial market aligns the intertemporal marginal rates of substitution of incumbent and final shareholders. The aggregate market value of firms $T=V u_{F}^{\prime}(\alpha V)$ is equal to aggregate dividends discounted at the shareholders' intertemporal MRS $\hat{Q}^{-1}$. An increase in $V$ strictly increases final shareholder welfare. If in addition $-C \cdot u_{F}^{\prime \prime}(C) / u_{F}^{\prime}(C) \leq 1$ for all $C$, then these welfare gains are passed on to incumbent shareholders through the aggregate market value of firms (i.e. at equilibrium, $\alpha T$ and $V(1-\alpha)$ are increasing functions of $V$ ). This justifies 
aggregate dividends as a measure of social welfare.

The endogenous choice of the fraction of shares $\alpha$ that are acquired by final shareholders aligns incumbent and final shareholders' marginal valuations in the aggregate, resulting in no mis-pricing of aggregate dividends. This result holds independently of how the shares of individual firms are traded. The absence of aggregate mis-pricing however does not preclude the possibility of mispricing of shares at the firm level.

2. Microstructure of equity markets: We assume that neither final nor incumbent shareholders have inside information in the firms, and the incumbent shareholders thus sell a fixed fraction $\alpha$ of each firm. Final shareholders do not actively manage their investments but invest through two types of funds, mutual funds and hedge funds. As the owner of all hedge funds and mutual funds, the final shareholders indirectly purchases the aggregate market portfolio of firms.

Mutual funds receive a stochastic inflow of funds and their investment strategies are strictly regulated: they invest by purchasing an equal number of equity shares in a fixed set of firms. The fraction of shares in firm $i$ that are purchased by mutual funds is given by $\alpha \Phi\left(u_{i}\right)$, where $u_{i} \sim \mathcal{N}\left(0, \delta^{-1}\right)$ denotes a random, firm-specific liquidity shock that is iid across firms. Hedge funds on the other hand acquire noisy private information about the different firms' fundamentals and then take positions in specific firms that are deemed sufficiently promising. There is a unit measure of such funds, who each obtain idiosyncratic private signals $x_{i} \sim \mathcal{N}\left(\theta_{i}, \beta^{-1}\right)$ about each firms' fundamental, after which (s)he decides in which firm to invest. To limit exposure to the risks associated with any individual firm, the hedge fund's positions are limited to no more than $\alpha$ shares per firm. ${ }^{12}$

The funds $\alpha T=\alpha \mathbb{E}\left(P_{i}\right)$ invested by final shareholders are split such that in the aggregate, $\mathbb{E}\left(\alpha \Phi\left(u_{i}\right) P_{i}\right)$ are invested by mutual funds who purchase a random fraction $\alpha \Phi\left(u_{i}\right)$ of the shares in firm $i$. The remainder is allocated to hedge funds. Each hedge fund in turn either invests its funds directly in firms by buying up to $\alpha$ units of equity, by lending to other hedge funds at a market rate $Q .{ }^{13}$ Hence a hedge fund will invest in firm $i$ if and only if its expectations about that firms' dividend satisfy $\mathbb{E}\left(\Pi\left(\theta_{i}, k_{i}\right) \mid x, P_{i}\right) \geq Q P_{i}$, resulting in a characterization of an indifference threshold $z$ that is a monotone function of the price $P_{i}$. As in section 2 , the equilibrium price is represented as a function of a sufficient statistic $z_{i}=\theta_{i}+1 / \sqrt{\beta} u_{i}$ and satisfies

$$
P_{i}\left(z_{i}, k_{i}\right)=\frac{1}{Q} \cdot \mathbb{E}\left(\Pi\left(\theta_{i}, k_{i}\right) \mid x=z_{i}, z_{i}\right)
$$

\footnotetext{
${ }^{12}$ Here we assume that the representative final shareholders' equity purchases through hedge funds and mutual funds scale with their aggregate demand for shares.

${ }^{13}$ This assumptions guarantees that all hedge funds have the same threshold return $Q$.
} 
Taking expectations and combining with $\mathbb{E}\left(P_{i}\right)=T=V \hat{Q}^{-1}$, the equilibrium value of $Q$ is

$$
Q=\hat{Q} \frac{\mathbb{E}\left\{\mathbb{E}\left(\Pi\left(\theta_{i}, k_{i}\right) \mid x=z, z\right)\right\}}{V} .
$$

Relative to the incumbent and final shareholders' inter-temporal MRS, the hedge funds' marginal return is distorted by a factor $\mathbb{E}\left\{\mathbb{E}\left(\Pi\left(\theta_{i}, k_{i}\right) \mid x=z, z\right)\right\} / V$ that corresponds to the ratio between the expected market value and the dividend value of firms.

3. Incumbent shareholders' decision problem: Incumbent shareholders of any given firm $i$ maximize expected cash flow from equity sale in stage 1 and dividends in stage 2 , weighted by their respective marginal utilities and taking the aggregate market values, $\alpha, V$ and $Q$ as given:

$$
\max _{k_{i} \geq 0} \mathbb{E}\left\{\alpha \hat{Q} P_{i}\left(z_{i}, k_{i}\right)+(1-\alpha) \Pi\left(\theta_{i}, k_{i}\right)\right\} .
$$

Substituting (8) into (10), this optimization problem takes the form

$$
\max _{k_{i} \geq 0}\left\{\alpha \frac{\hat{Q}}{Q} \mathbb{E}\left\{\mathbb{E}\left(\Pi\left(\theta_{i}, k_{i}\right) \mid x=z_{i}, z_{i}\right)\right\}+(1-\alpha) \mathbb{E}\left\{\Pi\left(\theta_{i}, k_{i}\right)\right\}\right\} .
$$

Hence, as in our partial equilibrium model, the incumbent shareholders maximize a weighted average of share price and dividend value. However, the relative weight on these two objectives depends not just on the fraction of shares sold $\alpha$, but also on the distortion between the hedge funds marginal return and their own inter-temporal marginal rate of substitution. This is because the market price $P_{i}\left(z_{i}, k_{i}\right)$ discounts future dividends at the hedge funds' marginal return which are not aligned at equilibrium with shareholders.

General equilibrium allocations are then fully characterized by values for $\alpha, Q$, and $k$ that solve the intertemporal equilibrium condition (7), the first-order condition for the firm's investment choice in (11), and the characterization of $Q$ in (9).

These micro-foundations rationalize the main assumptions of our partial equilibrium model in the context of a heterogeneous firm economy with no aggregate uncertainty by assuming that all shocks are firm-specific. Because final shareholders hold a representative portfolio of firms, their welfare is measured by aggregate dividends, and because the no-arbitrage principle still applies at the aggregate level, the value of aggregate dividends is passed on to incumbent shareholders through the aggregate market value of firms. Aggregation thus offers a justification for risk-neutrality w.r.t. the realized dividends from any given firm. ${ }^{14}$

\footnotetext{
${ }^{14}$ Our formulation also overcomes the recurrent critique that welfare discussions are incomplete without a proper specification of noise trader welfare. Here such concerns do not apply because (i) our model with delegated investment
} 
Within this aggregate model, we have then invoked a stylized view of delegated portfolio management, along with trading restrictions that limit exposures to specific firms, to justify our specific model of noisy information aggregation with portfolio constraints. While a full micro-foundation of such limits would take us too far afield, such restrictions may indeed be part of optimal delegation of decisions (Alonso and Matouschek, 2008, Amador and Bagwell, 2013).

\subsection{Investment distortions in general equilibrium: a pecuniary externality}

Next, we discuss how the decisions of shareholders in different firms interact with each other through the hedge funds' marginal return $Q$. If financial markets were efficient (in the sense that $\left.P_{i}\left(z_{i}, k_{i}\right)=Q^{-1} \cdot \mathbb{E}\left(\Pi\left(\theta_{i}, k_{i}\right) \mid z_{i}\right)\right)$, the same aggregation arguments as above imply that $Q=\hat{Q}$, i.e. hedge fund and incumbent shareholders' intertemporal marginal rates of substitution are aligned, and incumbent shareholders have an incentive to maximize expected dividends, i.e. $k=k^{*}$.

We can contrast this efficient market allocation with the equilibrium that results with market imperfections. To simplify the characterization, suppose that incumbent shareholder preferences are given by $v_{I}\left(C_{1}^{I}\right)+u_{I}\left(C_{2}^{I}\right)=\alpha_{0} \ln C_{1}^{I}+\left(1-\alpha_{0}\right) \ln C_{2}^{I}$ with $\alpha_{0} \in(0,1)$, so that their supply of equity shares is inelastic at $\alpha=\alpha_{0}$.

Consider the limiting case in which $\chi \rightarrow 0$. Let $V^{*}$ denote the first-best dividends, let $V_{P E}$ denote the level of dividends in partial equilibrium with $Q=\hat{Q}$ (characterized as $V$ in section 3), and $V_{G E}$ and $k_{G E}$ the general equilibrium level of dividends and investment.

\section{Proposition 5 Investment distortions in general equilibrium}

(i) Bounded distortions with upside risk: If $\mathbb{E}(\mathbb{E}(R(\theta) \mid x=z, z))>\mathbb{E}(R(\theta))$, then for small $\chi$, $C^{\prime}\left(k_{G E}\right) \approx \mathbb{E}(R(\theta))\left(1+\alpha_{0} \chi\right), V_{G E} / V^{*} \approx\left(1-\alpha_{0}\right) e^{\alpha_{0}}<1$, and $Q / \hat{Q} \rightarrow \infty$.

(ii) Unbounded distortions with downside risk: If $\mathbb{E}(\mathbb{E}(R(\theta) \mid x=z, z))<\mathbb{E}(R(\theta))$, then for small $\chi, C^{\prime}\left(k_{G E}\right) \approx \mathbb{E}(\mathbb{E}(R(\theta) \mid x=z, z))\left(1+\left(1-\alpha_{0}\right) \chi\right), V_{G E} / V_{P E} \rightarrow 0$, and $Q / \hat{Q} \rightarrow 0$.

This proposition shows how general equilibrium effects operating through the hedge funds' marginal return $Q$ interact with firm-level investment distortions. The result is based on two key observations. First, investment choices in individual firms exert a pecuniary externality on each other through their effect on $Q$. Second, the equilibrium value of $Q$ feeds back into the firm

interprets such shocks as resulting from random perturbations in mutual fund inflows, and (ii) from the perspective of the representative shareholder, noise trader losses are exactly offset by informed trader gains, both of which accrue to final shareholders, thus netting out from any welfare calculation. 
incentives, amplifying rent-seeking incentives in the case of downside risk, and dampening them in the case of upside risk.

To understand the origin of the pecuniary externality, we substitute (9) into (8). If we let $\hat{k}$ denote the aggregate investment level, we find the following expression for the share price of firm $i$ and the interaction between $k_{i}$ and $\hat{k}$ :

$$
P_{i}\left(z_{i}, k_{i}\right)=\frac{\mathbb{E}\left(\Pi\left(\theta_{i}, k_{i}\right) \mid x=z_{i}, z_{i}\right)}{\mathbb{E}\left\{\mathbb{E}\left(\Pi\left(\theta_{i}, \hat{k}\right) \mid x=z, z\right)\right\}} \cdot \hat{Q}^{-1} \cdot \mathbb{E}\left(\Pi\left(\theta_{i}, \hat{k}\right)\right)
$$

This characterization of the equilibrium price highlights how the rent-seeking objective of incumbent shareholders introduces a negative pecuniary externality: for a given aggregate market value of firms, incumbent shareholders in a specific firm gain from distorting investment to increase the market value of their own shares, but they do not internalize that if all firms engage in this behavior, then aggregate dividends will be lower, which lowers the aggregate market value of firms and hence their own aggregate welfare. The shareholders' rent-seeking incentives at the micro level turn out to be self-defeating in the aggregate. This feedback is similar to the collateral channel in Lorenzoni (2008) or the private trades channel of Farhi, Golosov and Tsyvinski (2009). But the origin of the pecuniary externality is different, as it emerges from market imperfections rather than incentive problems. In addition, the share price directly enters the firms' objective thereby affecting incentives to invest, rather than affecting investment indirectly through incentive or financial constraints.

Second, the pecuniary externality feeds back into the incumbent shareholders objective via the intertemporal investment wedge $Q / \hat{Q}$ that influences the relative weight associated with the share price. Without an intertemporal distortion, i.e. if $Q=\hat{Q}$, firms set marginal costs equal to $C^{\prime}(k)=\alpha_{0} \mathbb{E}\{\mathbb{E}(R(\theta) \mid x=z, z)\}+\left(1-\alpha_{0}\right) \mathbb{E}(R(\theta))$.

With upside risk, there is an upwards distortion in hedge fund interest rates, relative to the shareholders' intertemporal MRS, i.e. $Q>\hat{Q}$. This induces incumbent shareholders to place more weight on maximizing expected dividends, reduces the rent-seeking motive relative to the partial equilibrium analysis, and dampens investment distortions. Moreover (7) implies that expected dividends and share prices must be positive in general equilibrium, and that therefore the extent of over-investment cannot become too large. In other words, marginal costs $C^{\prime}(k)$ cannot stray too far from $\mathbb{E}(R(\theta))$, and in the limit as $\chi \rightarrow 0, C^{\prime}(k)$ must converge to $\mathbb{E}(R(\theta))$. In this limit, the intertemporal wedge becomes large $(Q / \hat{Q} \rightarrow \infty)$, dividends remain positive, yet strictly lower than at the first best, and investment remains distorted up by a factor $e^{\alpha_{0}}$ in the limit. Hence the general equilibrium effects offset a large part of the partial equilibrium investment distortion, but do not restore efficiency entirely. Depending on the fraction of shares traded in equilibrium, the 
welfare loss relative to first-best can still be very substantial. ${ }^{15}$

With downside risk, the distortion in hedge fund interest rates is downwards, $Q<\hat{Q}$. This pushes incumbent shareholders to shift even more weight on expected share prices, which reinforces the rent-seeking motive, and the associated pecuniary externality. In the limit as $\chi \rightarrow 0$, marginal costs $C^{\prime}(k)$ must converge to $\mathbb{E}(\mathbb{E}(R(\theta) \mid x=z, z))$. The amplification thus becomes so strong that it pushes shareholders to invest as if all their shares were sold in the market. Expected dividends vanish even relative to the partial equilibrium benchmark. ${ }^{16}$ The general equilibrium effects thus vastly amplify the partial equilibrium distortion.

To summarize, in general equilibrium, shareholder rent-seeking generates a pecuniary externality and an intertemporal investment distortion. The intertemporal distortion partly offsets the pecuniary externality in the case of upside risk, but reinforces it in the case of downside risk. Interestingly, and in contrast to the partial equilibrium analysis, the welfare consequences of market frictions are now more severe with downside risk, but limited with upside risk. And once again, returns to scale determine the severity of investment distortions and pecuniary externalities. The limiting results with $\chi \rightarrow 0$ illustrate that even small imperfections in equity markets can have very dramatic consequences for incentives, investment and welfare.

\subsection{Policy implications: general equilibrium}

General equilibrium forces align incumbent and final shareholder welfare with expected dividends: the conflicts of interests that arise over rent-seeking incentives in partial equilibrium disappear in the aggregate as welfare gains by final shareholders are passed on to incumbent shareholders through the aggregate market value of equity. At the same time, investment remains inefficient, and distortions may be amplified through a pecuniary externality.

Here, we discuss the general equilibrium effects associated with the policy interventions analyzed in section 3.2. We show that policies that improve shareholder incentives at the firm level may impair the financial market's role for intertemporal allocation of resources. This tradeoff becomes particularly salient in the case of downside risk.

For technical reasons, we assume that hedge funds, incumbent and final shareholders can store resources from stage 1 to stage 2 at a small, positive riskfree return $\bar{Q}>0$. This assumption insures that the hedge funds' lending rate $Q$ cannot fall below $\bar{Q}$, and that therefore the market and share-

\footnotetext{
${ }^{15}$ Recall that as $\chi \rightarrow 0, V_{P E} / V^{*} \rightarrow-\infty$ and $\hat{k} / k^{*} \rightarrow \infty$. Negative dividends are not possible in general equilibrium.

${ }^{16}$ Recall that $V / V^{*} \rightarrow 0$ as $\chi \rightarrow 0$. It is straight-forward to construct examples in which $V^{*} \rightarrow \infty$ as $\chi \rightarrow 0$, but $V_{G E} \rightarrow 0$, i.e. first-best dividends grow infinitely large, yet the realized surplus completely vanishes.
} 
holder discount rates always remain well defined. At the laissez-faire benchmark, this constraint is binding only in the case with downside risk and small $\chi$, where it limits the downwards adjustment of $Q$ that is needed to align aggregate market returns of equity with incumbent and final shareholders' intertemporal MRS. This pushes the market into a situation of excess demand for shares, as final shareholders become eager to buy the aggregate portfolio, but incumbent shareholders are unwilling to sell at depressed prices. Storage by incumbent and final shareholders implies that $\hat{Q}=1 / u_{F}^{\prime}\left(C_{F}^{2}\right) \geq \bar{Q}$, for otherwise final shareholders would strictly prefer storage over equity as a means to transfer wealth across time, but for small $\bar{Q}$, this constraint is never binding.

For a given value of $V$, an aggregate consumption allocation $\left(C_{I}^{1}, C_{I}^{2} ; C_{F}^{1}, C_{F}^{2}\right)$ for initial and final shareholders is feasible if it satisfies aggregate resource constraints $C_{I}^{1}+C_{F}^{1} \leq 0$ and $C_{I}^{2}+C_{F}^{2} \leq V$, and it satisfies intertemporal efficiency if no other feasible allocation yields strictly higher utility for both initial and final shareholders. Intertemporally efficient allocations must satisfy the resource constraints with equality, and equate initial and final shareholders' intertemporal marginal rates of substitution: $\hat{Q}=v_{I}^{\prime}\left(C_{I}^{1}\right) / u_{I}^{\prime}\left(C_{I}^{2}\right)=1 / u_{F}^{\prime}\left(C_{F}^{2}\right)$. The equilibrium characterized in section 4.1 satisfies intertemporal efficiency.

For any policy intervention, let $\left(T_{I}, V_{I}\right)$ and $\left(T_{F}, V_{F}\right)$ denote the aggregate market value and final dividends associated with equity sales and purchases from the incumbents' and final shareholders' perspective, respectively. Their first-order conditions w.r.t. $\alpha$ imply that an equilibrium allocation is intertemporally efficient if and only if $V_{I} / T_{I}=V_{F} / T_{F}$, i.e. the incumbent and final shareholders perceive the same ratio of market value at stage 1 to dividend value at stage 2 .

Policy interventions affect market allocations in two ways. First, they may drive a wedge between incumbent and final shareholders' market returns $V_{I} / T_{I}$ and $V_{F} / T_{F}$, and hence between their intertemporal marginal rates of substitution.

Second, they may cause the market to enter situations of excess demand or excess supply of equity shares, or even to break down completely if one side finds it optimal not to trade equity. These situations arise if there exists no $Q \geq \bar{Q}$, at which the firm-level valuation of equity shares is consistent with the incumbent and final shareholders' aggregate first-order conditions. Specifically, if $T_{I}$ is too low relative to $V_{I} / \hat{Q}$, then incumbent shareholders strictly prefer to hold on to their shares, although final shareholders may want to buy a positive amount. If $V_{F}$ is low relative to $T_{F} / u_{F}^{\prime}\left(C_{F}^{2}\right)$, final shareholders may prefer to stay out of the market and incumbent shareholders are unable to sell. Finally, if $T_{F}$ is low relative to $V_{F} u_{F}^{\prime}\left(C_{F}^{2}\right)$, the demand by final shareholders may exceed the amount of shares supplied by incumbent shareholders. In all these cases, the micro trading frictions prevent full adjustment of aggregate share prices. 
In a market breakdown, incumbent shareholders remain the final owners of the firms and therefore take efficient investment decisions. Market breakdown does not automatically cause intertemporal distortions, if resources can be re-allocated through other means, for example lump sum taxes and transfers. But efficiency in this case is not a market outcome and thus very different from the efficient markets benchmark.

The following proposition summarizes how the policies introduced in section 3.2 affect market outcomes in general equilibrium, when $\chi$ is small.

\section{Proposition 6 Policy interventions impair intertemporal trade}

(i)Regulatory policies: Regulatory policies that curb overinvestment in the case of upside risk $(\mathbb{E}(\mathbb{E}(R(\theta) \mid x=z, z))>\mathbb{E}(R(\theta)))$ improve efficiency without causing intertemporal distortions or market breakdowns. Regulatory policies that aim to reduce under-investment in the case of downside risk $(\mathbb{E}(\mathbb{E}(R(\theta) \mid x=z, z))<\mathbb{E}(R(\theta)))$ cause a market breakdown when $\chi$ is small $\left(T_{I} \leq 0\right)$.

(ii) Transaction taxes with upside risk: Transaction taxes and subsidies that curb (but do not eliminate) over-investment have no first-order effect on investment when $\chi$ is sufficiently small. Transaction taxes and subsidies that eliminate over-investment without causing intertemporal distortions require extreme transaction subsidies for some equity transactions.

(iii) Transaction taxes with downside risk: Transaction taxes and subsidies that seek to reduce under-investment must subsidize equity purchases, causing intertemporal distortions and an excess demand for shares by final shareholders $\left(T_{F} \leq 0\right)$ when $\chi$ is sufficiently small.

(iv) Market interventions with downside risk: For small $\chi$, equity purchases at a preset price that seek to curb underinvestment cause a market breakdown if they are not aggressive enough $\left(T_{I} \leq 0\right)$, or if they are too aggressive $\left(V_{F} \leq 0\right)$. For a middle range of intervention levels, the intervention causes over-investment, intertemporal distortions, and excess demand of shares $\left(V_{F} / T_{F} \rightarrow \infty\right)$, but the market remains in operation.

Regulatory policies do not interfere with market values, and therefore cannot cause intertemporal distortions (i.e. $T_{I}=T_{F}=T$ and $V_{I}=V_{F}=V$ ). In the case of upside risk they curb excess investment without disrupting equity markets. In the case of downside risk, however, they push firms to take investment decisions that are penalized by the stock market, i.e. the market prices in the additional investment cost, but not the full dividend return. When $\chi \rightarrow 0$, this causes aggregate stock prices to drop to zero, at which point incumbent shareholders withdraw from the market, whenever average investment costs exceed market returns: $C(k) / k \geq \mathbb{E}(\mathbb{E}(R(\theta) \mid x=z, z))$.

With tax interventions, as long as $V_{I}=V_{F}$, i.e. net of tax dividends are the same for incumbent 
and final shareholders, intertemporal efficiency holds if and only if the aggregate transaction tax revenue $T_{F}-T_{I}$ is zero. In the case of upside risk, general equilibrium forces already curb overinvestment to a large extent if $\chi$ is small. Thus, any attempt to influence investment incentives through tax policies is met one-for-one by an offsetting reduction in the corresponding general equilibrium adjustment. ${ }^{17}$ This is no longer the case if the tax policy targets the efficient level exactly, but such policies are only feasible with infinitely large subsidies on some equity trades. ${ }^{18}$

With tax interventions and downside risk, it is impossible to improve investment incentives without subsidizing equity purchases, when $\chi$ is sufficiently small. Moreover, the aggregate market value of equity (net of subsidies) can be smaller than the subsidy itself, so the pre-subsidy value of equity is negative. In effect the policy maker "bribes" final shareholders into purchasing the equity in order to enhance investment incentives for incumbent shareholders. At these prices and subsidies, the stock market becomes a free lunch for final shareholders who wish to purchase as much equity as they can get, but are limited to the quantity offered by incumbent shareholders. In the limit as $\chi \rightarrow 0$, we have $T_{I}-T_{F} \approx\left(C^{\prime}(k)-\mathbb{E}(\mathbb{E}(R(\theta) \mid x=z, z))\right) k$, so the policy is equivalent to directly subsidizing investment.

With market interventions, we characterize $\left(Q T_{I}, V_{I}\right)$ and $\left(Q T_{F}, V_{F}\right)$ as a function of the intervention threshold $\hat{z}$ and show that the intervention inevitably causes incumbent shareholders to withdraw from the market whenever $\hat{z}$ is less than some threshold $z_{1}>z^{*}$. It therefore becomes impossible to restore investment efficiency while relying on the stock market for intertemporal efficiency. It may seem paradoxical that an intervention meant to curb under-pricing at the level of individual firms actually exacerbates under-pricing in the aggregate. The reason this happens is due to the feedback from the intervention to investment and share prices: a market intervention that limits the most severe under-pricing also induces incumbent shareholder to invest more. For realizations of $z>\hat{z}$, the market prices in the higher investment cost without fully pricing in its returns, thus resulting in lower share prices. In the aggregate, when $\chi$ is small, this indirect effect dominates the direct effect of the intervention, lowering aggregate market values to the point that the market eventually breaks down.

An intervention with threshold $\hat{z}>z_{1}$ no longer causes incumbent shareholders to withdraw, but instead transforms the investment into an upside risk from the incumbent shareholders' perspective. There are now two possibilities depending on how the intervention influences equity returns to final

\footnotetext{
${ }^{17}$ This result follows from the fact that with upside risk and small $\chi, C^{\prime}\left(k_{G E}\right) \approx \mathbb{E}(R(\theta))\left(1+\alpha_{0} \chi\right)$, i.e. investment no longer responds to market returns.

${ }^{18}$ If the tax policy went so far as to under-shoot the efficient investment level, then general equilibrium forces will take over and amplify the resulting under-investment.
} 
shareholders. For very high intervention levels (i.e. when $\hat{z}$ exceeds some threshold $z_{2}>z_{1}$ ), the intervention drives up share prices and lowers equity returns for final shareholders causing them to withdraw from the market $\left(V_{F} \leq 0\right)$ - once again the market breaks down. For intermediate intervention levels, i.e. whenever $\hat{z} \in\left(z_{1}, z_{2}\right)$, instead drives up final shareholder returns on equity since the effect of the policy on final shareholder dividends dominates the effect on market values, to the point where equity (almost) becomes a free lunch again $\left(V_{F} / T_{F} \rightarrow \infty\right)$. Aggregate demand for shares then inevitably exceeds supply by incumbent shareholders. In this case, the intervention leads to over-investment and intertemporal distortions, but general equilibrium forces once again take over to limit how much over-investment the market intervention can cause: when $\chi$ is small, the intervention threshold $\hat{z} \in\left(z_{1}, z_{2}\right)$ does not affect investment to a first order. ${ }^{19}$

To summarize, with upside risk, regulatory interventions are well suited to curb over-investment, but general equilibrium forces mute the effectiveness of market-based interventions. With downside risks, attempts to enhance investment without fully compensating shareholders for the marginal investment cost depress aggregate share prices and cause incumbent shareholders to withdraw from the market. Attempts to enhance investment incentives while compensating incumbent shareholders (directly through transaction taxes or indirectly through market interventions) require subsidies that turn equity into a free lunch for final shareholders: equity demand then far exceeds available supply. Finally, extreme market interventions may completely crowd out final shareholders from equity markets, once again resulting in a market breakdown. The scope for policy makers to intervene without disrupting intertemporal trade is therefore extremely limited when $\chi$ is sufficiently low. Perhaps the only good way to reconcile investment incentives and intertemporal efficiency may be to directly subsidize firms for their investment without intervening in financial markets.

\section{$5 \quad$ Extensions}

In this section, we develop several extensions of our baseline partial equilibrium model to illustrate how shareholder rent-seeking incentives can shed light on important aspects of firm behavior. Unless

\footnotetext{
${ }^{19}$ The argument for how how market interventions cause intertemporal distortions is particularly easy to see when $\chi$ is bounded away from zero and $\lim _{\theta \rightarrow-\infty} R(\theta)>\mathbb{E}(R(\theta)) /(1+\chi)$, in which case equity prices are always strictly positive and the market does not break down. Since the policy generates negative expected revenues we have $Q\left(T_{I}-T_{F}\right)>V_{I}-V_{F}$. Moreover, for downside risks, we have $Q T_{I}>V_{I}$ for any intervention such that $\hat{z} \leq z^{*}$. Since the intervention must occur at a positive price we also have $T_{I}>T_{F}$, and from these three inequalities it follows immediately that $V_{I} / T_{I}<V_{F} / T_{F}$. The policy effectively subsidizes incumbent shareholders, inducing them to sell a larger part of their equity share than would be efficient intertemporally.
} 
otherwise noted, final dividends are the same as in section 3 , and we set $\alpha=1$, i.e. incumbent shareholders care only about the market value of their equity share.

\subsection{Leverage and Risk-Taking}

We first consider a version of our model, in which investment is funded by borrowing. As our primary result we show how frictions in equity markets dilute the disciplining effects of credit spreads. In fact, leverage turns out to be a tool of choice for shareholders to both scale up investment and shift equity returns to the upside, thus inflating its market value.

At the first stage the firm has cash reserves $w$, and chooses to invest $k \geq 0$ in a project to obtain a stochastic cash flow $R(\theta) k$ at the final stage. Throughout this section, we assume that $R(\cdot)=$ $\bar{R} \cdot R_{0}(\cdot)$ where $R_{0}(\cdot)$ has symmetric risks with support $[0,2]$ and $\bar{R}>0$, so that $\mathbb{E}(R(\theta))=R(0)=$ $\bar{R} / 2$, and without borrowing, frictions in equity markets do not distort shareholder incentives. If $k>w$, the difference $k-w$ must be funded by borrowing from external lenders. The loan contract is subject to costly state verification: lenders incur a cost $\varepsilon R(\theta) k$ to verify the firm's realized cash flows ex post. The loan contract $(b, B)$ specifies an initial loan size $b \geq k-w$ and a promised repayment $B$. Such a contract determines a leverage ratio $w / k=w /(w+b)$ and a default threshold $\hat{\theta}$, such that $B=R(\hat{\theta}) k$. Whenever $\theta \geq \hat{\theta}$, the lender is repaid in full while the borrower earns dividends $R(\theta) k-B$. Whenever $\theta<\hat{\theta}$, the borrower defaults and earns 0 , and the lender monitors the borrower and recovers the cash flows net of monitoring costs, $(1-\varepsilon) R(\theta) k$.

We assume that lenders and borrowers (shareholders) do not discount between the initial and final stages. the lender breaks even whenever

$$
\frac{b}{k} \leq(1-\varepsilon) \int_{-\infty}^{\hat{\theta}} R(\theta) d \Phi(\sqrt{\lambda} \theta)+R(\hat{\theta})(1-\Phi(\sqrt{\lambda} \hat{\theta})) .
$$

Combined with the constraint on the initial loan size, this yields the following restriction on the firm's leverage ratio $w / k$ :

$$
\frac{w}{k} \geq 1-\mathbb{E}(R(\theta))+\varepsilon \int_{-\infty}^{\hat{\theta}} R(\theta) d \Phi(\sqrt{\lambda} \theta)+\int_{\hat{\theta}}^{\infty}(R(\theta)-R(\hat{\theta})) d \Phi(\sqrt{\lambda} \theta)
$$

Suppose that the RHS of this inequality is strictly positive everywhere, so that there exists no loan contract at which the project is completely self-funding.

Borrowing without market frictions: In the benchmark without market frictions, the borrower/shareholders' expected dividend is $k \int_{\hat{\theta}}^{\infty}(R(\theta)-R(\hat{\theta})) d \Phi(\sqrt{\lambda} \theta)$, and the expected return on cash reserves $w$ is

$$
\rho(w / k, \hat{\theta})=(k / w) \cdot \int_{\hat{\theta}}^{\infty}(R(\theta)-R(\hat{\theta})) d \Phi(\sqrt{\lambda} \theta) .
$$


Figure 2: Optimal Lending with Costly State Verification
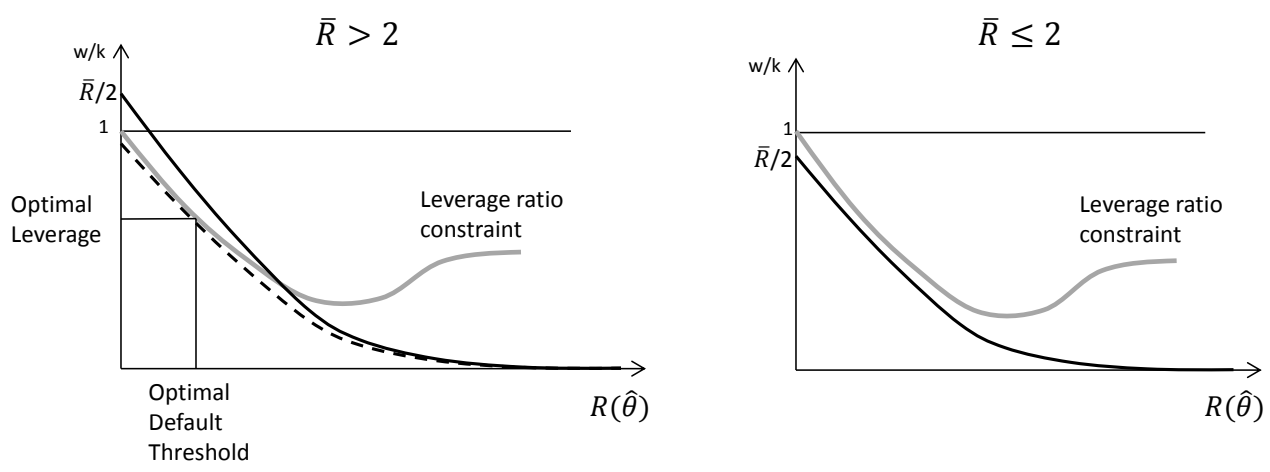

The optimal contract from the shareholders' perspective maximizes $\rho(w / k, \hat{\theta})$ subject to (14), and determines an optimal leverage ratio or investment level $k^{*}$ and default threshold $\theta^{*}$. The firm borrows and invests if and only only if $\rho\left(w / k^{*}, \theta^{*}\right)>1$. We recall the following standard results:

(i) Credit restrictions: If $\bar{R}>2$, the loan size is endogenously restricted (relative to an infinite investment level at first-best), due to the leverage ratio constraint.

(ii) Investment in projects with positive excess returns: If $\bar{R} \leq 2$, the firm does not invest and prefers to hold cash.

(iii) Disciplining effect of credit spreads: The optimal loan contract achieves the second-best, i.e. $\theta^{*}$ and $k^{*}$ maximize social surplus by optimally trading off loan size against bankruptcy costs.

Figure 2 illustrates the optimal lending contract. We represent contracts as pairs of leverage ratio $w / k$ and repayment promise $\hat{R} \equiv R(\hat{\theta})$. A lender breaks even only with contracts that lie on or above the leverage ratio constraint, which is represented by the grey curve. The borrower only accepts contracts that lie on or below the solid black line, at which the shareholder's expected returns on internal funds equal 1 . In the left panel, when $\bar{R}>2$, the grey and black curves intersect, so there exist loan contracts that allow the borrower to earn excess returns and the lender to break even. The borrowers' indifference curves over different contracts with different return levels $\rho$ simply scale the solid black line by $\rho^{-1}$, The borrowers' return on internal funds is maximized at the tangency point between the grey and the dashed black line. In the right panel, $\bar{R} \leq 2$, and there exists no contract to which the two parties would ever agree.

If after the contracting stage debt and equity claims are traded in financial markets at prices 
Figure 3: Lending with information aggregation frictions in equity markets

$\bar{R}>2$

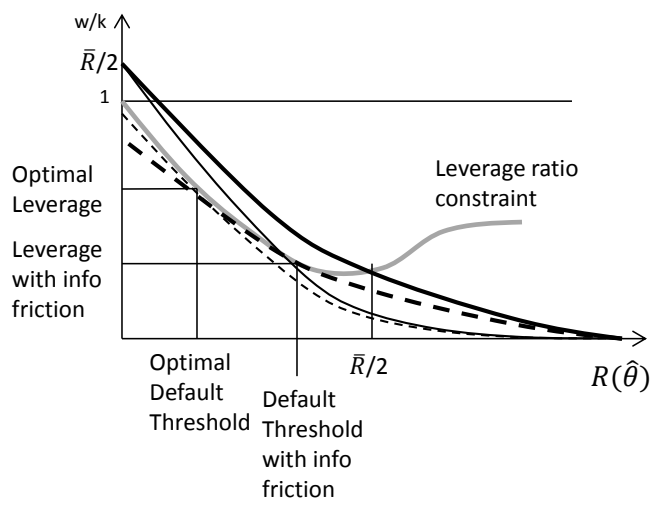

$\bar{R} \leq 2$

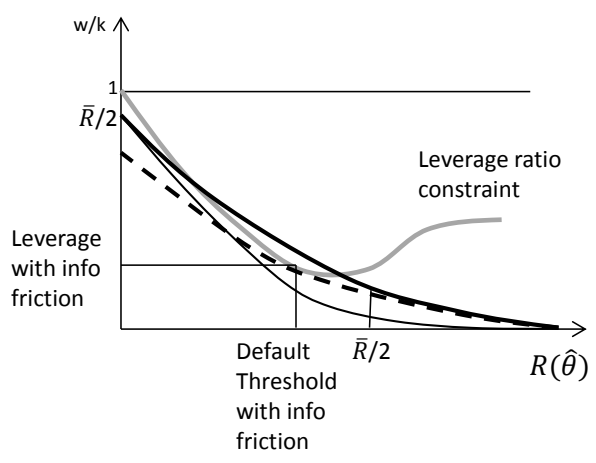

equal to conditional expectations of their corresponding cash flows, such markets do not alter the original lenders' break-even constraint, the borrowers' incentives, or the optimal loan contract. Efficient financial markets thus impose market discipline on borrowers and lenders to agree on a loan contract that maximizes the social surplus from the firm's investment.

Borrowing with equity market frictions. Suppose now that the initial borrowers sell their equity share in a market with information aggregation frictions. The lenders on the other hand hold their claim to maturity, so their break-even constraint is unchanged. Following proposition 1, the equity claim is priced at $P(k, z)=k \cdot \mathbb{E}(\max \{R(\theta)-R(\hat{\theta}), 0\} \mid x=z, z)$, and the expected market value of equity is $k \int_{\hat{\theta}}^{\infty}(R(\theta)-R(\hat{\theta})) d \Phi\left(\sqrt{\lambda_{P}} \theta\right)$, where $\lambda_{P}^{-1}>\lambda^{-1}$ parametrizes information frictions in the equity market as in section 3.1. We then obtain the following proposition:

\section{Proposition 7 Equity market frictions cause excessive leverage.}

(i) Excessive leverage If $\bar{R}>2$, then $\hat{k}>k^{*}$ and $\hat{\theta}>\theta^{*}$ and $\hat{k}$ and $\hat{\theta}$ are increasing in $\lambda_{P}^{-1}$.

(ii) Inefficient investment: There exists a bound $\tilde{R} \in(1,2)$, such that if $\bar{R} \in(\tilde{R}, 2]$ and $\lambda_{P}^{-1}$ is sufficiently large, incumbent shareholders borrow and invest $\hat{k}>w$.

Equity market frictions thus distort borrower incentives. First, shareholders seek excessive leverage because the market friction flattens the shareholders' tradeoff between leverage and default risk. Second, if market frictions are sufficiently severe, shareholders choose to invest even in projects with negative excess returns in order to chase upside gains. 
Figure 3 illustrates the effects of financial market frictions on shareholder incentives. The thin black line corresponds to the shareholders' indifference curve for $\rho=1$ without equity market frictions. The thick black line plots the shareholders' indifference curve for a return of 1 on internal funds with market frictions. The difference between the solid thin and thick black lines corresponds to the shareholder rents. These rents are maximized when equity only includes upside risk, i.e. $\hat{R}=\bar{R} / 2$. The shareholders' indifference curve in the $(w / k, \hat{R})$-plane have the same intercepts as without equity market frictions, but are flatter for $\hat{R}<\bar{R} / 2$ and steeper for $\hat{R}>\bar{R} / 2$, thus raising expected returns on cash-holdings for any possible loan contract.

In the left panel, $\bar{R}>2$, so it is efficient to invest. The flattening of shareholders' indifference curves shifts their preferred contract to the right, with a higher leverage ratio and a higher default threshold than would be optimal otherwise. Shareholders' expected returns increase, and they are more willing to accept higher default risk in return for leverage because the marginal increase in borrowing costs is partly offset by a shift towards upside risk and over-pricing of equity. Because shareholders do not fully internalize the marginal costs of default, they opt for excessive leverage.

In the right panel, $\bar{R} \leq 2$, returns are too low to make the investment profitable. Nevertheless shareholders decide to borrow and invest, and even accept very high leverage and credit spreads in order to take advantage of upside risk and extract shareholder rents. In other words, credit spreads lose their disciplining role on borrowers. The threshold return $\tilde{R} / 2<1$ above which such inefficient investments become desirable for incumbent shareholders is a a function of the monitoring cost $\varepsilon$ and the shape of the return function in its lower tail, and varies between $1 / 2$ and 1 .

To summarize, leverage allows incumbent shareholders to increase their rents through two channels: it scales up risk-taking through a higher value of $\hat{k}$, and it shifts equity returns to the upside which increases expected over-pricing for a given investment level. By taking a levered bet, incumbent shareholders capture rents from final shareholders with the complicity of lenders. Equity market frictions thus undermine market discipline imposed through credit spreads. ${ }^{20}$

\subsection{Managerial Incentives and Agency Costs}

The corporate finance literature identifies agency frictions between shareholders and managers as the central source of imperfections in firm decision-making. With efficient financial markets, shareholders should then be given full discretion to design managerial incentive contracts.

\footnotetext{
${ }^{20}$ Information frictions in bond markets would have counter-vailing effects, as they would induce original lenders to over-estimate the tail risk of default. See Albagli, Hellwig and Tsyvinski (2014) for bond pricing with noisy information aggregation in a dynamic variant of this model.
} 
Here, we argue that our main results about shareholder incentives are robust to the inclusion of such agency frictions. In our model, agency costs do not alter the shareholders' rent-seeking incentives, since these derive from return perceptions in the market, which are independent of interactions between shareholders and managers.

At the same time, our model offers a contrarian perspective to the laissez-faire approach to contract design: The same contracts that are quintessential for managerial incentives in efficient markets now serve to optimize shareholder rents, and therefore it may be desirable to regulate executive compensation contracts. And whereas agency frictions are costly from a social planners' perspective when markets are efficient, here they may actually improve firm performance if they curb shareholder incentives to extract rents.

We illustrate these points with a principal-agent variant of our baseline model from section 2 . Incumbent shareholders delegate the choice of the investment scale $k \geq 0$ to a risk-neutral manager. They pay the manager a wage $W(\cdot)$ that is contingent on the realization of final dividends $\Pi$, but must satisfy the manager's participation condition $\mathbb{E}(W(\Pi(\theta, k))) \geq \bar{W}$. We first assume that incumbent shareholders can always implement their preferred action at no additional cost, and then enrich the model to allow for managerial moral hazard.

Contract design without agency frictions. Let $\underline{k}$ and $\bar{k}$ be defined by $C^{\prime}(\underline{k})=\lim _{\theta \rightarrow-\infty} R(\theta)$ and $C^{\prime}(\bar{k})=\lim _{\theta \rightarrow \infty} R(\theta)$. It is straight-forward to show that incumbent shareholders can use equity, options or compensation caps to implement any $k \in(\underline{k}, \bar{k})$ with an expected wage payment that satisfies $\mathbb{E}(W(\Pi(\theta, k)))=\bar{W}$. A contract of the form $W^{*}(\Pi)=\omega_{0}+\omega_{1} \Pi$ that is linear in final dividends, i.e. a vested equity share that the manager cannot sell in the market, implements the efficient investment level $k^{*}$. A contract of the form $W(\Pi)=\omega_{0}+\omega_{1} \max \{\underline{\Pi}, \Pi\}$, corresponding to a vested stock option, induces upwards distortions in investment, implementing any $k \in\left(k^{*}, \bar{k}\right)$ with different values of $\underline{\Pi}$. A contract of the form $W(\Pi)=\omega_{0}+\omega_{1} \min \{\bar{\Pi}, \Pi\}$ with a cap on total compensation implements downwards distortions $k \in\left(\underline{k}, k^{*}\right)$. In each of these cases, the choices of $\omega_{0}$ and $\omega_{1}$ serve to equate the expected wage payment $\mathbb{E}(W(\Pi(\theta, k)))$ to $\bar{W}$.

Incumbent shareholders are thus able to implement their optimal $\hat{k}$ through flexible design of the optimal compensation contract. If $\hat{k}>k^{*}$, the incumbent shareholders' optimal contract adds a minimal compensation level into the benchmark contract $W^{*}(\Pi)$ to strengthen incentives and increase investment above $k^{*}$. If instead $\hat{k}<k^{*}$, the incentives provided by $W^{*}(\Pi)$ are too strong from the incumbent shareholders' perspective, and therefore the optimal contract includes a cap on total compensation. With market frictions, such incentive pay schemes for managers thus become an important tool to optimize shareholder rents. 
Of course it is well known that these contracts serve to taylor the manager's risk-taking incentives. But whereas an efficient markets view interprets these contracts as part of a socially efficient incentive scheme to reign in managerial moral hazard, with market imperfections they emerge as the tool of choice to extract excessive shareholder rents. ${ }^{21}$

If incumbent shareholders design CEO compensation to incentivize rent-seeking, then regulating the design of executive compensation contracts offers an additional policy margin to curb investment distortions. In fact, a regulator can implement $k^{*}$ by restricting executive compensation to be of the form $W^{*}(\Pi)$, regardless of the risks faced by the firm. In effect, this restriction limits executive compensation to a combination of base pay and a vested equity share, with a complete ban on options or compensation caps that seek to distort risk-taking incentives. A restriction to linear contracts is also quasi necessary if shareholders can always scale the compensation contract so that expected compensation is at $\bar{W}$. Otherwise, any contract that allows a firm to even marginally distort investment in the desired direction will be strictly preferred to $W^{*}(\Pi)$.

Restricting CEO compensation to restricted equity has one important advantage over other policy measures: it is a simple one-size-fits-all policy that allows the policy maker to implement the efficient investment level $k^{*}$ without any inside knowledge of firm returns, technologies or market frictions. Regulatory interventions, transaction taxes or market interventions instead all require that the policy maker is able to identify and target the efficient investment level $k^{*}$. This is an important distinction from the other interventions we discussed, which all required far more firmspecific information about firm characteristics and market frictions that is tyically proprietary to the firm and difficult to ellicit by an ouside regulator. This issue only gets compounded when firm decisions become more complex and based on proprietary information that is not directly accessible to the regulator. The need for this information arises because the intervention offsets the original distortion with a second distortion which needs to be finely adjusted to the firm's characteristics.

Regulation of executive compensation instead tackles the problem at its root by targeting the CEO's objective function and directly limiting the shareholder's ability to incentivize rent-shifting. By aligning CEO incentives with the social planner's objective, the regulator no longer has to worry about how market frictions affect incentives.

\footnotetext{
${ }^{21}$ Since any investment level can be implemented without agency costs through a П-contingent contract, investment distortions do not result from an artificial restriction on the contract space. Implementation possibilities only expand with a richer contract space, say by conditioning compensation on share prices ( $P$-contingent contracts). For example, the shareholders' preferred investment level $\hat{k}$ could also be implemented through a participation in the share sale (though this requires that $k$ is perfectly observable to make sure that prices internalize variation in $k$ ).
} 
Contract design with managerial moral hazard. Suppose now that the manager can divert the investment funds $C(k)$ to enjoy a private benefit $b C(k)$. The wage contract $W(\Pi)$ must therefore satisfy $\mathbb{E}(W(\Pi(\theta, k))) \geq \max \{b C(k), \bar{W}\}$, and $\hat{k} \in \operatorname{argmax}_{k} \mathbb{E}(W(\Pi(\theta, k)))$. We will focus on the implementation of $k$ s.t. $b C(k) \geq \bar{W}$.

The optimal contract design problem can be analyzed in the usual two-step procedure. First, for each $k$, let $w(k)$ denote the minimal expected wage cost that implements the choice of $k$, subject to the manager's incentive compatibility and participation constraints:

$$
\begin{gathered}
\qquad w(k)=\min _{W(\cdot)} \mathbb{E}(W(\Pi(\theta, k))) \\
\text { s.t. } k \in \operatorname{argmax}_{k^{\prime}} \mathbb{E}\left(W\left(\Pi\left(\theta, k^{\prime}\right)\right)\right) \text { and } \mathbb{E}(W(\Pi(\theta, k))) \geq b C(k)
\end{gathered}
$$

Using the same contracts as above, any $k \in(\underline{k}, \bar{k})$ can be implemented with a contract that pays in expectation $w(k)=\mathbb{E}(W(\Pi(\theta, k)))=b C(k)$. Second, we determine the investment scale $\hat{k}$ that maximizes the expected share price net of the wage cost:

$$
\hat{k} \in \operatorname{argmax}_{k^{\prime}} \mathbb{E}\left\{\mathbb{E}(\Pi(\theta ; k) \mid x=z, z)-w\left(k^{\prime}\right)\right\} .
$$

The optimal investment $\hat{k}$ satisfies the first order condition $\mathbb{E}(\mathbb{E}(R(\theta) \mid x=z, z))=C^{\prime}(\hat{k})+$ $w^{\prime}(\hat{k})=(1+b) C^{\prime}(\hat{k})$, and therefore modifies the marginal cost of investment by the marginal wage cost associated with higher investment. The efficient (second-best) investment $k^{*}$ satisfies the first-order condition $\mathbb{E}(R(\theta))=C^{\prime}\left(k^{*}\right)+w^{\prime}\left(k^{*}\right)=(1+b) C^{\prime}\left(k^{*}\right)$. Thus investment distortions are entirely due to distortions in the incumbent shareholders' objective. All our previous results are robust, once the marginal cost of investment is adjusted to include the agency cost component: Upside risk results in over-investment, downside risk in under-investment, and the easier it is to scale investment, the more pronounced the distortions are. Both $\hat{k}$ and $k^{*}$ are decreasing functions of $b$, i.e. the agency friction increases marginal costs and thereby reduces both the chosen and the efficient investment level. Expected dividends are $\mathbb{E}(R(\theta)) \hat{k}-(1+b) C(\hat{k})$.

If agency frictions reign in rent-seeking incentives, they may even increase firm dividends.

\section{Proposition 8 If upside risks are easily scaleable, agency frictions increase efficiency.}

Expected dividends are increasing in $b$, whenever $\mathbb{E}\{\mathbb{E}(R(\theta, e) \mid x=z, z)\} / \mathbb{E}(R(\theta))>1+\chi$.

Thus, agency frictions unambiguously increase welfare if there is upside risk and $\chi$ is sufficiently small. ${ }^{22}$ The agency friction has two effects on welfare. On the one hand, it increases

\footnotetext{
${ }^{22}$ This condition is equivalent to (4) with $\alpha=1$ in prop. 2 , which determines whether overall surplus is negative.
} 
the cost of investment, resulting in a direct welfare change $-d b \cdot C(\hat{k})<0$ for a marginal increase in agency costs $d b>0$. On the other hand, an increase in agency costs $d b>0$ also reduces investment by $d \hat{k}=-(1+b)^{-1} \cdot C^{\prime}(\hat{k}) / C^{\prime \prime}(\hat{k}) \cdot d b<0$, which changes welfare by $d \hat{k} \cdot(\mathbb{E}(R(\theta))-\mathbb{E}(\mathbb{E}(R(\theta) \mid x=z, z)))$. With over-investment, this second term is positive, and it dominates if $\chi$ is sufficiently small. The opposite scenario arises with under-investment: the two effects compound each other, and agency frictions worsen investment distortions. ${ }^{23}$

These results extend to other models with agency frictions between shareholders and managers. The key observation is that the resulting principal-agent problem can be broken down into a first step of minimizing the wage costs of implementing any given investment choice, and a second step of selecting the shareholders' optimal investment choice, given agency and market frictions. Since market frictions only appear in the second stage problem, they do not affect the determination of agency costs at the first stage. ${ }^{24}$

The benefits of regulating executive compensation are also robust to the presence of non-trivial agency frictions. As long as market frictions introduce a wedge between initial shareholders' incentives and social surplus, a social planner will gain from limiting shareholder discretion in executive contract design. The optimal limits on discretion may however need to balance shareholder rentseeking against managerial moral hazard. In this context, the vested equity contract remains approximately optimal when $b$ is low, i.e. when concerns over shareholder rent-seeking outweigh concerns over managerial moral hazard, and thus represents a useful benchmark against which to measure the costs and benefits of shareholder discretion.

\subsection{Social Value of Public Information}

We now consider the impact of public information on market prices, expected market returns and investment. At the efficient markets benchmark, better information improves firms' investment decisions and is unambiguously welfare improving. With frictions in equity markets, public in-

\footnotetext{
${ }^{23}$ In fact, this comparative static argument extends to other comparative statics of the cost function: if investment costs $C(k, b)$ as a function of some reduced form parameter $b$ satisfy $C_{k b}(k, b)>0$, then an increase in $b$ raises investment costs and lowers investment incentives, which can generate welfare gains if it reduces over-investment. The same argument thus also suggests that with over-investment, technological improvements that lower investment costs need not be welfare-improving, if better technologies lead to more rent extraction.

${ }^{24}$ Here we have assumed that the manager is paid by incumbent shareholders. If instead the manager is paid by final shareholders, then dividends are $\Pi-W$, the share price is $P(z ; k)=\mathbb{E}(\Pi-W \mid x=z, z)$, and incumbent shareholders evaluate the cost of the managers' wage through the lens of market expectations. The wage contract then provides a tool for shifting upside and downside risk between shareholders and managers, but otherwise the analysis remains unchanged.
} 
formation disclosures may instead have adverse welfare effects: more accurate information enables firms to make better investment decisions, but this information can also be mis-used as an additional margin along which incumbent shareholders optimize their rent. If the rent-seeking motive is sufficiently important, enhanced transparency is welfare increasing only once the information is sufficiently precise to crowd the market-generated signal $z$ out from investor expectations.

Formally, suppose that incumbent shareholders and outside investors can condition their decisions on a public signal $y \sim \mathcal{N}\left(\theta, \kappa^{-1}\right)$. Suppose also that $R(\cdot)$ is strictly convex, so that returns are dominated by upside risk regardless of the realization of $y$. The equilibrium share prices and optimal investment decisions $k(y)$ are characterized as before in proposition 1 and equation 3, once beliefs are conditioned on $y$ as well as $z \cdot{ }^{25}$ The share price $P(y, z ; k)$ and expected dividend value $V(y, z ; k)$ take the form $P(y, z ; k)=\mathbb{E}(R(\theta) \mid x=z, z, y) \cdot k-C(k)$ and $V(y, z ; k)=\mathbb{E}(R(\theta) \mid z, y) \cdot k-C(k)$. The price thus overweighs the market information $z$, but underweighs the public signal $y$.

The efficient investment decision $k^{*}(y)$ maximizes $\mathbb{E}(V(y, z ; k))$, solving the first-order condition $C^{\prime}\left(k^{*}(y)\right)=\mathbb{E}(R(\theta) \mid y)$, and the first-best value is $\mathbb{E}\left(V^{*}(y)\right)=\frac{\chi}{1+\chi} \mathbb{E}\left(\mathbb{E}(R(\theta) \mid y)^{1+1 / \chi}\right)$.

The incumbent shareholders maximize the expected market price, conditional on $y$ : $C^{\prime}(\hat{k}(y))=$ $\mathbb{E}\{\mathbb{E}(R(\theta) \mid x=z, z, y) \mid y\}$. Expected dividend value is $V(y)=\mathbb{E}(R(\theta) \mid y) \hat{k}(y)-C(\hat{k}(y))$.

Our next proposition compares expected dividend values with a public signal, $\mathbb{E}(V(y))$ to expected dividends without a public signal, $V$, as characterized in section 3. If $\chi$ is sufficiently low, then the provision of the public signal results in strictly lower expected dividend.

Proposition 9 If upside risks are easily scaleable, better public information reduces expected dividends but increases expected share prices.

For any $\kappa>0$, there exists $\chi(\kappa)>0$ such that if $\chi<\chi(\kappa), \mathbb{E}(V(y))<V<0$ and $\mathbb{E}(P(y, z ; \hat{k}(y)))>\mathbb{E}(P(z, \hat{k}))>0$.

Moreover $\lim _{\chi \rightarrow 0} \mathbb{E}(V(y)) / V=\lim _{\chi \rightarrow 0} \mathbb{E}(P(y, z ; \hat{k}(y))) / \mathbb{E}(P(z, \hat{k}))=\infty$.

Although better information reduces the investment risk incumbent shareholders are exposed to, and thus enables them to take better decisions, this does not guarantee an overall welfare improvement if better information also increases rent-seeking. The proposition shows that when there are upside risks and $\chi$ is sufficiently close to zero (so that expected dividends are negative), then the effect of public information on rent-seeking dominates the direct efficiency gains, resulting in lower overall welfare. In fact the social losses resulting from better information can become

\footnotetext{
${ }^{25}$ That is, $\theta \mid y \sim \mathcal{N}\left(\kappa /(\lambda+\kappa) y ;(\lambda+\kappa)^{-1}\right)$ and $y \sim \mathcal{N}\left(0 ; \lambda^{-1}+\kappa^{-1}\right)$
} 
arbitrarily large. Better public information is welfare-improving only once it is sufficiently precise to crowd out the market signal $z$ from prices and align market and fundamental returns to investment.

Scaleability is a double-edged sword in relation to transparency. On the one hand, the potential efficiency gains from better information - if the firm were to take the efficient investment decision increase with scaleability and become very large in the limit (i.e. $\lim _{\chi \rightarrow 0} \mathbb{E}\left(V^{*}(y)\right) / V^{*}=\infty$ ). But on the other hand, the potential for mis-using information for rent-seeking purposes also increases with scaleability. Simply put, the easier it is for a decision maker to scale the risks, the more the decision maker has to gain from incorporating additional information. But this principle applies just as much to the social planner who maximizes expected dividends as it applies to the incumbent shareholders who maximize the expected share price.

Proposition 9 contributes to the literature on the social value of public information. Morris and Shin (2002) and Angeletos and Pavan (2007) show that public disclosures may be welfarereducing, if strategic complementarities distort agents' responses to information. Although Morris and Shin (2002) cite financial markets as a leading motivation for the reduced-form zero-sum coordination motives embedded in the beauty contest game, coordination in financial markets was not modeled explicitly. Amador and Weill (2010) obtain a similar result but focus on informational externalities. Proposition 9 also features a distortion in the response to public information, but the welfare losses arise because of the rent-seeking behavior by shareholders, not coordination motives or informational externalities.

\subsection{Stock-Price Sensitivity of Investment}

A large empirical literature explores the sensitivity of firm decisions, in particular corporate investment, to share prices. ${ }^{26}$ One possible explanation for such investment sensitivity to stock prices is information feedback: the share price contains valuable information that helps shareholders and managers make more informed investment decisions. ${ }^{27}$ In this context, investment sensitivity to stock prices is not a symptom of inefficiency but the result of socially efficient information processing. Here, we allow for informational feedback from the share price to investment and consider how market frictions distort the use of information aggregated through share prices. $^{28}$

We modify our benchmark model by assuming that the initial shareholders publicly commit to

\footnotetext{
${ }^{26}$ See Morck et al. (1990), Baker, Stein and Wurgler (2003), and Gilchrist, Himmelberg, and Huberman (2005).

${ }^{27}$ See Dow and Gorton (1997), Dow and Rahi (2003), Goldstein and Guembel (2008), Foucault and Fresard (2012), and Goldstein, Ozdenoren, and Yuan (2013).

${ }^{28}$ This application subsumes results from the working paper Albagli, Hellwig, and Tsyvinski (2011a).
} 
a price-contingent, or equivalently $z$-contingent investment function $k(z) .{ }^{29}$ Market participants perfectly anticipate the investment level that will realize at a given price, and the incumbent shareholders internalize the impact of their decision rule on the share price. ${ }^{30}$ For a given $k(z)$, the equilibrium share price is $P(z, k(z))=\mathbb{E}(R(\theta) \mid x=z, z) \cdot k(z)-C(k(z))$. The expected dividend is $V(z, k(z))=\mathbb{E}(R(\theta) \mid z) \cdot k(z)-C(k(z))$.

Information Feedback. To illustrate the effect of information feedback, we compare expected dividends and shareholder rents with an increasing investment function $k(z)$, with a benchmark in which investment is constant at $\hat{k}=\mathbb{E}(k(z))$. The expected dividend takes the form

$$
\mathbb{E}(V(z, k(z)))=\mathbb{E}(V(z, \hat{k}))+\operatorname{cov}(k(z), \mathbb{E}(R(\theta) \mid z))-(\mathbb{E}(C(k(z)))-C(\hat{k}))
$$

The information feedback increases expected dividends by $\operatorname{cov}(k(z), \mathbb{E}(R(\theta) \mid z))>0$ relative to the constant investment case, and it reduces expected dividends by a term due to convexity of costs. The covariance term measures the value of conditioning investment on $z$, which strictly exceeds the second term if investment is not too volatile. Expected dividends increase because the information feedback aligns marginal costs and investment more closely with expected returns.

Likewise, we can characterize the effect of information feedback on expected shareholder rents: $\mathbb{E}(P(z, k(z)))-\mathbb{E}(V(z, k(z)))=\mathbb{E}(P(z, \hat{k}))-\mathbb{E}(V(z, \hat{k}))+\operatorname{cov}(k(z), \mathbb{E}(R(\theta) \mid x=z, z)-\mathbb{E}(R(\theta) \mid z))$

If $R(\cdot)$ is symmetric and $\mathbb{E}(R(\theta) \mid x=z, z) \geq \mathbb{E}(R(\theta) \mid z)$ for $z \geq 0$, then this covariance is strictly positive. Information feedback thus generates endogenous upside risk: the firm invests more when $z$ is high and expected market returns exceed fundamental returns. ${ }^{31}$ This reinforces the incumbent shareholders' rent extraction incentive and increases shareholder rents. Moreover,

\footnotetext{
${ }^{29}$ This requires implicitly that the price function is strictly monotone in $z$, a condition that is not automatically satisfied for all $k(z)$. Alternatively one may assume that shareholders have the means to infer $z$ through other means than the price, or that there exists a "non-strategic" component of dividends $\pi(\theta)$ that is strictly increasing in $\theta$ and guarantees an upwards-sloping price function. Here we will ignore the invertibility issue, but note that monotonicity is satisfied via an envelope condition for the case of primary interest, where $\alpha=1$ and incumbent shareholders maximize expected share price. See Albagli, Hellwig, and Tsyvinski (2011a) for further discussion.

${ }^{30}$ This commitment could result from internal reporting and decision procedures that make it difficult to reverse the initial decision ex post, or from the design of executive contracts at the initial stage. Importantly, we assume that final shareholders are not able to renegotiate investment or incentive contracts before the investment is made, even though they would want to do so.

${ }^{31}$ For general return distributions, $\operatorname{cov}(k(z), \mathbb{E}(R(\theta) \mid x=z, z)-\mathbb{E}(R(\theta) \mid z))$ is non-negative and can be arbitrarily large whenever (i) $k(z)$ is sufficiently responsive to $z$, and (ii) $\mathbb{E}(R(\theta) \mid x=z, z)>\mathbb{E}(R(\theta) \mid z)$ for sufficiently large realizations of $z$.With symmetric or upside risk, information feedback generates or strengthens the upside bias in market prices. With downside risk, information feedback mitigates or overturns downwards bias in prices.
} 
shareholder rents are increasing in the sensitivity of $k(\cdot)$ to $z$. The efficient investment rule sets $k^{*}(z)$ such that $C^{\prime}\left(k^{*}(z)\right)=\mathbb{E}(R(\theta) \mid z)$ and incorporates the information contained in the price according to Bayes' Rule. As in section 5.3, returns to scale increase the potential value of information feedback, i.e. $\lim _{\chi \rightarrow 0} \mathbb{E}\left(V\left(z, k^{*}(z)\right)\right) / V^{*}=\infty$, but simultaneously increases shareholder rents, i.e. $\lim _{\chi \rightarrow 0} \mathbb{E}\left(P\left(z, k^{*}(z)\right)-V\left(z, k^{*}(z)\right)\right)=\infty$. Thus even if the original returns are dominated by downside risk, incumbent shareholders in equilibrium capture arbitrarily large positive rents if investment is sufficiently easy to scale up.

Investment Distortions with Informational Feedback. Next, we discuss how rent-seeking by incumbent shareholders leads to excess sensitivity of investment to stock prices. Suppose that $R(\cdot)$ is such that $\mathbb{E}(R(\theta) \mid x=z, z) / \mathbb{E}(R(\theta) \mid z)$ is strictly increasing in $z$.

The initial shareholders choose $\hat{k}(z)$ to satisfy $C^{\prime}(\hat{k}(z))=\mathbb{E}(R(\theta) \mid x=z, z)$. Therefore, investment $\hat{k}(z)$ is dictated by market expectations of investment returns: investment responds more to $z$ than would be justified by Bayes' Rule. In effect, information feedback with imperfect equity markets results in a theory of endogenous catering effects (see, e.g. Stein 1996): Capital market imperfections distort market valuations, and with information feedback, incumbent shareholders and managers have an incentive to cater investment decisions to these distorted market expectations of returns in an attempt to maximize shareholder rents.

We obtain a positive relation between investment and share prices: $\hat{k}(z)=((1+1 / \chi) P(z))^{1 /(1+\chi)}$. Expected returns on equity are $\frac{V(z)}{P(z)}-1=\frac{1+\chi}{\chi}\left(\frac{\mathbb{E}(R(\theta) \mid z)}{\mathbb{E}(R(\theta) \mid x=z, z)}-1\right)$, and hence decreasing in investment and share price. The following proposition summarizes the economic effects of information feedback for investment and equity returns.

\section{Proposition 10 Information feedback causes excess investment volatility}

(i) Investment is increasing in share prices: $\operatorname{cov}(\hat{k}(z), P(z))>0$.

(ii) Excess sensitivity of investment to stock prices: $\hat{k}(z) / k^{*}(z)$ is increasing in $z$.

(iii) Higher Investment leads to lower equity returns: $\operatorname{cov}\left(\hat{k}(z), \frac{V(z)-P(z)}{P(z)}\right)<0$.

Our model merges the predictions of information feedback theories with models of catering to investor sentiments. Market signals convey valuable information to shareholders. But these signals are not unbiased and result in a catering of investment to market expectations of returns. Information feedback thus results in excess sensitivity of investment, higher expected share prices and shareholder rents, and lower subsequent returns. Proposition 10 summarizes these predictions.

Information feedback gives incumbent shareholders an additional margin along which to optimize their rents. Since shareholder rents are increasing in the sensitivity of investment to $z$, they 
take advantage through an investment rule that caters to market expectations. This causes excess volatility in investment: on the upside, shareholders over-invest to maximize the rents they extract from inflated share prices. On the downside, they under-invest to limit the losses they incur from the market price being below the fundamental value. Our model thus links investment volatility to stock market volatility by tying investment decisions to market expectations of returns.

Several papers confirm these empirical predictions. First, there is evidence in support of information feedback: Chen, Goldstein and Jiang (2007) find that real investment is more sensitive to share prices in firms whose shares are traded by more informed traders, as measured by PIN (probability of informed trading - Easley et al. (1996)). Roll, Schwartz and Subrahmanayam (2009) provide evidence that deeper options markets for a firm's share stimulate the entry of informed traders, and that such firms have a higher sensitivity of investment to share prices. These papers suggest that the equity market indeed conveys information about fundamentals that guide corporate investment decisions. Second, Polk and Sapienza (2009) offer direct support for catering effects in corporate investment by estimating the regression coefficients in proposition $10(i)$ and (iii). Using discretionary accruals as a proxy for mispricing, they find a positive relation between share overvaluation and investment after controlling for Tobin's Q. ${ }^{32}$ This relation is stronger for firms with higher share turnover. Moreover, firms with high investment subsequently have low share returns, the more so the larger is their measure of mispricing. This suggests that such investment behavior is indeed inefficient.

The catering channel not only increases investment volatility but also weakens the connection between investment and fundamental returns. A high price translates into a higher investment level, but if the market is sufficiently noisy, prices may be almost exclusively driven by market noise, and carry little information about fundamentals. Investment nevertheless responds aggressively in order to capture rents on the upside or limit losses on the downside. In the limiting case where investment is orthogonal to fundamentals, the feedback from prices to investment leads to large positive shareholder rents, and large negative dividend values.

\subsection{Time-inconsistent firm decisions}

With efficient markets, share prices perfectly align the interests of successive shareholder generations and optimal firm decisions are time-consistent. At each date, the controlling generation of

\footnotetext{
${ }^{32}$ Discretionary accruals measure the extent to which a firm has abnormal non-cash earnings. Firms with high discretionary accruals typically have relatively low share returns in the future, suggesting that discretionary accruals artificially drive up prices temporarily.
} 
shareholders can thus be trusted to take decisions that also reflect the interests of the future owners of the firm. Here we argue that market frictions can cause firm decisions to be time-inconsistent in the short-run. Evidently the rent-seeking by incumbent shareholders has a negative effect on future shareholders, but in turn, the anticipation of decisions taken by future shareholders also feed back into current shareholders' valuations and rents. The non-cooperative solution of the game between successive shareholder generations then leads to a Pareto-inferior equilibrium.

We augment our model to include two decision stages, one controlled by incumbent shareholders before shares have been traded, and one controlled by final shareholders after shares have been traded. The firm's final dividend is $\Pi\left(\theta ; k_{I}, k_{F}\right)=R_{I}(\theta) k_{I}-C_{I}\left(k_{I}\right)+R_{F}(\theta) k_{F}-C_{F}\left(k_{F}\right)$, where $k_{I}$ is the initial investment decision controlled by incumbent shareholders and $k_{F}$ the second investment decision controlled by final shareholders. The surplus-maximizing choice $k_{I}^{*}$ and $k_{F}^{*}(z)$ satisfies $C_{I}^{\prime}\left(k_{I}^{*}\right)=\mathbb{E}\left(R_{I}(\theta)\right)$ and $C_{F}^{\prime}\left(k_{F}^{*}(z)\right)=\mathbb{E}\left(R_{F}(\theta) \mid z\right)$. The decision rules that maximize the expected market value of the firm and incumbent shareholder payoffs is instead given by $C_{I}^{\prime}\left(\hat{k}_{I}\right)=$ $\mathbb{E}\left(\mathbb{E}\left(R_{I}(\theta) \mid x=z, z\right)\right)$ and $C_{F}^{\prime}\left(\hat{k}_{F}(z)\right)=\mathbb{E}\left(R_{F}(\theta) \mid x=z, z\right)$.

Consider now the dynamic game in which incumbent shareholders first choose $\widetilde{k}_{I}$ as Stackelberg leaders, and final shareholders then choose $\widetilde{k}_{F}(z)$ contingent the realization of the market price (and correspondingly, $z$ ). Because the choices are additively separable, we have $C_{I}^{\prime}\left(\widetilde{k}_{I}\right)=$ $\mathbb{E}\left(\mathbb{E}\left(R_{I}(\theta) \mid x=z, z\right)\right)$ and $C_{I}^{\prime}\left(\widetilde{k}_{F}(z)\right)=\mathbb{E}\left(R_{F}(\theta) \mid z\right)$, or $\widetilde{k}_{I}=\hat{k}_{I}$ and $\widetilde{k}_{F}(z)=k_{F}^{*}(z)$. The final shareholders set $k_{F}^{*}(z)$ at the efficient level, but incumbent shareholders distort $\widetilde{k}_{I}$ to increase shareholder rents. The following proposition shows that the equilibrium of decisions made by successive shareholder generations lies strictly below the Pareto frontier. It can therefore not be rationalized as an optimal time-consistent plan that maximizes a weighted average of incumbent and final shareholder welfare.

\section{Proposition 11 Market Frictions cause dynamically inconsistent firm behavior}

Unless $\hat{k}_{I}=k_{I}^{*}$, the equilibrium choices $\widetilde{k}_{I}$ and $\widetilde{k}_{F}(z)$ are strictly Pareto-inferior.

The intuition for the result is as follows. Imagine that our incumbent and final shareholders could get together to agree on a joint perturbation from the equilibrium in such a way that each marginally changes their investment in the direction preferred by the other, i.e. incumbent shareholders set $k_{I}$ a bit closer to $k_{I}^{*}$ and final shareholders set $k_{F}(z)$ a bit closer to $\hat{k}_{F}(z)$. The change in $k_{I}$ reduces incumbent shareholder rents associated with incumbent shareholder investment $k_{I}$ but the change in $k_{F}(z)$ increases the shareholder rents associated with the final investment $k_{F}(z)$. If $\hat{k}_{I} \neq k_{I}^{*}$, we can calibrate the two perturbations so that they exactly offset each other, leaving 
final shareholders with the same expected payoffs as at the equilibrium.

Now, incumbent shareholders' payoffs are the sum of expected dividends plus expected shareholder rents. By construction the perturbations leave total shareholder rents unchanged, but they affect expected dividends. If $\hat{k}_{I} \neq k_{I}^{*}$, the change in $k_{I}$ strictly increases $\mathbb{E}\left(R_{I}(\theta)\right) k_{I}-$ $C_{I}\left(k_{I}\right)$, resulting in a first-order welfare gain. The change in $k_{F}(z)$ on the other hand lowers $\mathbb{E}\left[\mathbb{E}\left(R_{F}(\theta) \mid x=z, z\right) k_{F}(z)-C_{F}\left(k_{F}(z)\right)\right]$, but since the perturbation departs from $k_{F}^{*}(z)$, the loss is of second-order. Hence the perturbation strictly benefits incumbent shareholders.

To summarize, when rent-seeking incentives induce a conflict of interest between successive shareholder generations, the resulting equilibrium can be inefficient and result in dynamically inconsistent firm behavior. As in the case of consumers with time-inconsistent preferences, endogenous preference reversals generate a positive value to commitment. Here, the current generation of shareholders would like to increase the current share prices, while future shareholders would like to increase final dividends. With market frictions these two objectives differ and with lack of commitment, the resulting conflict of interest results in behavior that lies strictly inside the Pareto frontier. Under these circumstances, final shareholders and the social planner would like to influence incumbent shareholders, and we have discussed means to do so through regulatory and policy interventions. But incumbent shareholders would also like to influence the final shareholders' behavior to their advantage, i.e. generate commitment to future policies. Such commitment is privately valuable to incumbent shareholders, but socially harmful, if it enforces rent-seeking strategies that are in the interest of incumbent shareholders, but do not maximize social surplus. ${ }^{33}$

\subsection{Information rents, liquidity shocks, and shareholder disagreement}

So far, we have focused on the gap between $P(z, k)$ and $V(z, k)$ as the source of distortions and abstracted from proprietary information by incumbent shareholders, their exposure to liquidity shocks or disagreement among incumbent shareholders. Here we argue that shareholder information or liquidity shocks may alter the nature of rents and distortions but not their impact on firm decisions. Furthermore, heterogeneity in exposures to liquidity shocks or access to private information leads to heterogeneous rent-seeking incentives, generating disagreement and conflict of interests among

\footnotetext{
${ }^{33}$ Time-inconsistency and value to commitment can arise from market friction even if the identity of the controlling shareholder does not change. For example, suppose that all decisions are controlled by a long-lived incumbent owner who floats a minority share $\alpha<1 / 2$ of the firm in the market. This incumbent owner will want to commit ex ante to a strategy that maximizes a weighted average of the market value and fundamental value of the firm, but once the share $\alpha$ is sold, he would want to re-optimize the subsequent decisions to maximize the firm's fundamental value.
} 
shareholders. Such conflicts of interest necessarily disappear with efficient financial markets.

We can decompose expected payoffs of informed traders and noise traders in our model as follows. An informed trader's expected payoff prior to receiving her private signal, which corresponds to the informed traders' average payoff in the market, is

$$
\begin{aligned}
I(z, k) & =\int \max \left\{0, \mathbb{E}\left(\Pi(\theta, k) \mid x^{\prime}, z\right)-P(z)\right\} d F\left(x^{\prime} \mid z\right) \\
& =k \cdot \int_{z}^{\infty}\left(\mathbb{E}\left(R(\theta) \mid x^{\prime}, z\right)-\mathbb{E}(R(\theta) \mid x=z, z)\right) d F\left(x^{\prime} \mid z\right)
\end{aligned}
$$

where $F(x \mid z)$ denotes the distribution of the private signal $x$, conditional on $z \cdot{ }^{34} I(z, k)$ corresponds to the option value of buying on private information, is strictly positive and exceeds the expected payoff to all buyers, $V(z, k)-P(z, k)=k \cdot \int_{-\infty}^{\infty}\left(\mathbb{E}\left(R(\theta) \mid x^{\prime}, z\right)-\mathbb{E}(R(\theta) \mid x=z, z)\right) d F\left(x^{\prime} \mid z\right)$. The noise traders expected payoff $V(z, k)-P(z, k)-I(z, k)$ is unambiguously negative.

Using this decomposition of buyer payoffs we extend our analysis to alternative assumptions about information and liquidity shocks:

1. Private information by incumbent shareholders: Suppose incumbent shareholders receive a private signal before deciding whether to sell their equity share. Shares are bought by a random measure of noise traders, $\Phi(u)$. In this case, the supply of shares is given by $\operatorname{Pr}(x<\hat{x}(P) \mid \theta)=$ $\Phi(\sqrt{\beta}(\hat{x}(P)-\theta))$, while demand is $\Phi(u)$. The equilibrium characterization remains the same, with $\hat{x}(P)=z=\theta+1 / \sqrt{\beta} \cdot u$. But the initial shareholders' payoff is $P(z, k)+I(z, k)>V(z, k)$, while the buyers' (noise traders') payoff is $V(z, k)-P(z, k)-I(z, k)<0$. In other words, the initial shareholder rents are no longer given by the gap between expected price and dividend value, but by the option value of selling on private information, $P(z, k)-V(z, k)+I(z, k)$. This value is strictly positive and scales with $k$, so the initial shareholders now have a strict incentive to over-invest in order to capture a larger information rent regardless of the firm's risk characteristics.

2. Liquidity shocks to incumbent shareholders: Suppose next that a random fraction $1-\Phi(u)$ of incumbent shareholders has to sell. Potential buyers of equity shares observe private signals: their demand for shares is $\operatorname{Pr}(x>\hat{x}(P) \mid \theta)=1-\Phi(\sqrt{\beta}(\hat{x}(P)-\theta))$. The equilibrium characterization remains the same, with $\hat{x}(P)=z=\theta+1 / \sqrt{\beta} \cdot u$, but the initial shareholder objective changes to $V(z, k)-I(z, k)$, while the informed buyers earn $I(z, k)$. In this case, the incumbent shareholders have an incentive to under-invest to reduce information rents conceded to informed buyers.

3. Disagreement among shareholders: If shareholders differ ex ante in their investment horizons, their access to private information, or their exposure to liquidity shocks, then this heterogeneity leads to disagreement among shareholders about the desired investment decisions. Each incumbent

\footnotetext{
${ }^{34}$ Note that $x \mid z \sim \mathcal{N}\left(\beta \delta /(\lambda+\beta \delta) \cdot z ; 1 /\left((\lambda+\beta \delta)^{-1}+\beta^{-1}\right)\right)$
} 
shareholder will have their own preferred value of $k$. A voting perspective would suggest the implementation of the value of $k$ that is preferred by the median shareholder. The departure from efficient markets is crucial for the emergence of shareholder disagreement: Under efficient markets, shareholder rents disappear, and hence shareholder incentives are all aligned with social surplus. Financial market frictions therefore play an important role in shaping disagreement between concurrent shareholders of a firm.

\section{Conclusion}

With unlimited arbitrage, equity markets can be trusted to accurately reflect firm fundamentals, and shareholders can then be trusted to adequately represent social welfare. This connection provides the intellectual basis for shareholder value as a measure of social surplus, and for the laissez-faire argument against interference with firm decisions. Its validity as a guiding principle for regulatory policy rests on the unstated assumption that departures from market efficiency cannot be too important, and have at best minor effects on shareholder incentives.

In this paper we question this implicit assumption by taking a different view of price formation in asset markets that is based on limits to arbitrage and noisy information aggregation. We argue that limits to arbitrage introduce a rent-seeking motive to shareholder value: markets no longer fully align shareholder value with social surplus, and initial shareholders can no longer be trusted to act in the interest of future shareholders or society. What's more, even small departures from market efficiency can have large aggregate consequences either through firm-level returns to scale, or through pecuniary externalities in general equilibrium. Our theory offers a new rationale for regulating corporate behavior or for policy interventions in the market that is not present when financial markets are efficient, though in general equilibrium, these policies face a fine tradeoff between enhancing investment incentives and disrupting equity markets.

While our departure from market efficiency is well grounded in empirical studies about limits to arbitrage and asset pricing anomalies, the implications of our model for corporate behavior are consistent with mounting evidence on how firm decisions react to market prices. In particular, we show how rent-seeking by controlling shareholders gives rise to lack of self-control, corporate short-termism, endogenous preference reversals, and conflicts of interests between shareholders elements of decision-making by firms that are well documented in reality and amply discussed in the literature, yet difficult to rationalize in a context of efficient financial markets.

We have illustrated the implications of our theory with a few particularly stark applications 
to excess leverage, separation of ownership and control, social value of public information or stock price sensitivity of investment. Yet there may be many other decisions for which such distortions may be potentially relevant, such as capital structure, dividend payout policies, or real effects of credit distortions. We view our model as a first step towards assessing the consequences of financial market imperfections for firm behavior and welfare, and towards designing adequate policies to regulate shareholder incentives where necessary.

\section{References}

[1] Albagli, Elias, Christian Hellwig, and Aleh Tsyvinski (2011a). "Information Aggregation, Investment, and Managerial Incentives," NBER Working paper No. 17330.

[2] Albagli, Elias, Christian Hellwig, and Aleh Tsyvinski (2011b). "A Theory of Asset Prices based on Heterogeneous Information," NBER Working paper No. 17548.

[3] Albagli, Elias, Christian Hellwig, and Aleh Tsyvinski (2014). "Dynamic Dispersed Information and the Credit Spread Puzzle," NBER Working paper No. 19788.

[4] Alonso, Ricardo, and Niko Matouschek (2008). "Optimal Delegation." Review of Economic Studies, 75(1), 259-293.

[5] Amador, Manuel, and Kyle Bagwell (2013). "The Theory of Optimal Delegation with an Application to Tariff Caps." Econometrica, 81(4), 1541-1599.

[6] Amador, Manuel, and Pierre-Olivier Weill (2010). "Learning from Prices: Public Communication and Welfare." Journal of Political Economy, 118(5), 866-907.

[7] Angeletos, George-Marios, and Alessandro Pavan (2007). "Efficient Use of Information and Social Value of Information." Econometrica, 75(4), 1103-1142.

[8] Asriyan, Vladimir (2016). "Balance Sheet Recessions with Informational and Trading Frictions." working paper, CREI/UPF, Barcelona.

[9] Baker, Malcolm, Jeremy Stein, and Jeffrey Wurgler (2003). "When Does the Market Matter? Stock Prices and the Investment of Equity-Dependent Firms," Quarterly Journal of Economics, 118(3), 969-1005. 
[10] Baker, Malcolm, and Jeffrey Wurgler (2013). "Behavioral Corporate Finance: an Updated Survey," in: Handbook of Economics and Finance (Constantinides, Harris, Stulz, eds.), Elsevier, Vol. 2 A, 357-424.

[11] Becht, Marco, Patrick Bolton, and Ailsa Roell (2003). "Corporate Governance and Control," in: Handbook of Economics and Finance (Constantinides, Harris, Stulz, eds.), Elsevier, Vol. 1 A, 1-109.

[12] Benmelech, Efraim, Eugene Kandel, and Pietro Veronesi (2010). "Share-Based Compensation and CEO (Dis)Incentives," Quarterly Journal of Economics, 125 (4), 1769-1820.

[13] Biais, Bruno, Larry Glosten, and Chester Spatt (2005). "Market Microstructure: A Survey of Microfoundations, Empirical Results, and Policy Implications," Journal of Financial Markets, $8(2), 217-264$.

[14] Bolton, Patrick, Jose Scheinkman, and Wei Xiong (2006). "Executive Compensation and ShortTermist Behaviour in Speculative Markets," Review of Economic Studies, 73(3), 577-610.

[15] Chen, Qi, Itay Goldstein, and Wei Jiang. "Price Informativeness and Investment Sensitivity to Stock Price," Review of Financial Studies, 20(3), 619-650.

[16] D'Avolio, Gene (2002). "The Market for Borrowing Stock," Journal of Financial Economics, $66(2-3), 271-306$.

[17] Dávila, Eduardo, and Anton Korinek (forthcoming). "Pecuniary Externalities in Economies with Financial Frictions," Review of Economic Studies.

[18] Derrien, Francois, Ambrus Kecskes and David Thesmar (2013). "Investor Horizons and Corporate Policies," Journal of Financial and Quantitative Analysis, 48(6), 1755-1780.

[19] Diamond, Douglas, and Robert Verrecchia (1981). "Information Aggregation in a Noisy Rational Expectations Economy," Journal of Financial Economics, 9 (3), 221-235.

[20] Dow, James, and Gary Gorton (1997). "Share Market Efficiency and Economic Efficiency: Is There a Connection?," The Journal of Finance, 52 (3), 1087-1129.

[21] Dow, James, and Rohit Rahi (2003). "Informed Trading, Investment, and Welfare," Journal of Business, 76(3), 439-454. 
[22] Easley, David, Nicholas Kiefer, Maureen O’hara, and Joseph Paperman (1996). "Liquidity, Information, and Infrequently Traded Stocks," Journal of Finance, 51(4), 1405-1436.

[23] Farhi, Emmanuel, Mikhail Golosov, and Aleh Tsyvinski (2009). "A Theory of Liquidity and Regulation of Financial Intermediation," Review of Economic Studies, 76(3), 973-992.

[24] Foucault, Thierry, and Laurent Frésard (2012). "Cross-Listing, Investment Sensitivity to Stock Price, and the Learning Hypothesis," Review of Financial Studies, 25(11), 3305-3350.

[25] Gale, Douglas, and Martin Hellwig (1985). "Incentive-Compatible Debt Contracts: The OnePeriod Problem," Review of Economic Studies, 52(4), 647-663.

[26] Geanakoplos, John, and Herakles Polemarchakis (1986). "Existence, Regularity, and Constrained Suboptimality of Competitive Allocations when the Asset Market is Incomplete," in: Uncertainty, Information and Communication - Essays in honor of Kenneth J. Arrow, Vol. III (Heller, Starr and Starrett, eds.), Cambridge University Press.

[27] Gilchrist, Simon, Charles P. Himmelberg, and Gur Huberman (2005). "Do Stock Price Bubbles Influence Corporate Investment?.” Journal of Monetary Economics, 52(4), 805-827.

[28] Goldstein, Itay and Alexander Guembel (2008). "Manipulation and the Allocational Role of Prices," Review of Economic Studies, 75(1), 133-164.

[29] Goldstein, Itay, Emre Ozdenoren, and Kathy Yuan (2013). "Trading Frenzies and Their Impact on Real Investment," Journal of Financial Economics, 109(2), 566-582.

[30] Greenwald, Bruce, and Joseph Stiglitz (1986). "Externalities in Economies with Imperfect Information and Incomplete Markets," Quarterly Journal of Economics, 101(2), 229-264.

[31] Grossman, Sanford J. and Joseph E. Stiglitz (1980). "On the Impossibility of Informationally Efficient Markets," American Economic Review, 70 (3), 393-408.

[32] Gul, Faruk, and Wolfgang Pesendorfer (2001). "Temptation and Self-Control." Econometrica, 69 (6), 1403-1435.

[33] Gul, Faruk, and Wolfgang Pesendorfer (2005). "The Revealed Preference Theory of Changing Tastes." Review of Economic Studies, 72 (2), 429-448.

[34] Hellwig, Martin (1980). "On the Aggregation of Information in Competitive Markets," Journal of Economic Theory, 22, 477-498. 
[35] Holmstrom, Bengt, and Jean Tirole (1993). "Market Liquidity and Performance Monitoring," Journal of Political Economy, 101(4), 678-709.

[36] Kyle, Albert S. (1985). "Continuous Auctions and Insider Trading." Econometrica, 53(6), 1315-1335.

[37] Lorenzoni, Guido (2008). "Inefficient Credit Booms," Review of Economic Studies, 75(3), 809833.

[38] Milgrom, Paul (1981). "Rational Expectations, Information Acquisition, and Competitive Bidding," Econometrica, 49 (4), 921-943.

[39] Morck, Randall, Shleifer, Andrei, Vishny, Robert, Shapiro, Matthew, and James Poterba (1990). "The Stock Market and Investment: is the Market a Sideshow?" Brookings Papers on Economic Activity, 1990(2), 157-215.

[40] Morris, Stephen, and Hyun Song Shin (2002). "Social Value of Public Information," American Economic Review, 92(5), 1521-1534.

[41] Nagel, Stefan (2013). "Empirical Cross-Sectional Asset Pricing," Annual Review of Financial Economics, 5, 167-199.

[42] Polk, Christopher and Paola Sapienza (2009). "The Share Market and Corporate Investment: A Test of Catering Theory," Review of Financial Studies, 22(1), 187-217.

[43] Pontiff, Jeffrey (1996). "Costly Arbitrage: Evidence from Closed-End Funds," Quarterly Journal of Economics, 111 (4), 1135-1151.

[44] Roll, Richard, Eduardo Schwartz, and Avanidhar Subrahmanyam (2009). "Options Trading Activity and Firm Valuation," Journal of Financial Economics, 94(3), 345-360.

[45] Schwert, William (2003). "Anomalies and Market Efficiency," in: Handbook of Economics and Finance (Constantinides, Harris, Stulz, eds.), Elsevier, Vol. 1 B, 939-974.

[46] Stein, Jeremy (1988). "Takeover Threats and Managerial Myopia," Journal of Political Economy, 96 (1), 61-80.

[47] Stein, Jeremy (1989). "Efficient Capital Markets, Inefficient Firms: A Model of Myopic Corporate Behavior," Quarterly Journal of Economics, 104 (4), 655-669. 
[48] Stein, Jeremy (1996). "Rational Capital Budgeting in an Irrational World," Journal of Business, 69 (4), 429-455.

[49] Tirole, Jean (2006). "Theory of Corporate Finance," Princeton Economic Press.

[50] Townsend, Robert M. (1979). "Optimal Contracts and Competitive Markets with Costly State Verification," Journal of Economic Theory, 21(2), 265-293.

[51] Wurgler, Jeffrey and Ekaterina Zhuravskaya (2002). "Does Arbitrage Flatten Demand Curves for Stocks," Journal of Business, 75(4), 583-608.

\section{Appendix: Proofs}

\section{Proof of Proposition 1:}

Let $\hat{x}(P)$ denote the private signal of a trader who is just indifferent between buying and not buying the share at a given price $P$, so that $P=\int \Pi(\theta, k) d H(\theta \mid \hat{x}(P), P)$. Since $R(\cdot)$ is increasing in $\theta, \int \Pi(\theta, k) d H(\theta \mid x, P)$ must be monotone in $x$, and any trader whose private signal exceeds $\hat{x}(P)$ must strictly prefer to purchase a share, while any trader whose signal is less than $\hat{x}(P)$ prefers not to buy. Thus, the total demand by the informed traders is $\alpha(1-\Phi(\sqrt{\beta}(\hat{x}(P)-\theta)))$. Equating demand and supply, a price $P$ clears the market in state $(\theta, u)$ if and only if $\hat{x}(P)=\theta+1 / \sqrt{\beta} \cdot u \equiv z$. Therefore, in any equilibrium, it must be the case that $\hat{x}(P(\theta, u ; k))=z$, and if $P$ is a function of $z$ only, then it must be invertible. But if $P(\cdot)$ is invertible, observing $P$ is informationally equivalent to observing $\hat{x}(P)=z \sim \mathcal{N}\left(\theta,(\beta \delta)^{-1}\right)$. Along the equilibrium path, the traders thus treat the signals $\hat{x}(P) \sim \mathcal{N}\left(\theta,(\beta \delta)^{-1}\right)$ and $x \sim \mathcal{N}\left(\theta, \beta^{-1}\right)$ as mutually independent normal signals and their posterior beliefs $H(\cdot \mid x, P)$ are given by

$$
\theta \mid x, P \sim \mathcal{N}\left(\frac{\hat{\lambda} \mu+\beta x+\beta \delta \hat{x}(P)}{\hat{\lambda}+\beta+\beta \delta},(\hat{\lambda}+\beta+\beta \delta)^{-1}\right) .
$$

Substitute $\hat{x}(P)=z$, we restate the informed traders' indifference condition in terms of $z: P(z, k)=$ $\mathbb{E}(\Pi(\theta, k) \mid x=z, z)$. The expression for $V(z, k)=\mathbb{E}(\Pi(\theta, k) \mid z)$ is derived analogously using only the information from the market signal, $\theta \mid P \sim \mathcal{N}\left(\frac{\hat{\lambda} \mu+\beta \delta \hat{x}(P)}{\hat{\lambda}+\beta \delta},(\hat{\lambda}+\beta \delta)^{-1}\right)$.

Uniqueness. If demand is restricted to be non-increasing in $P, \hat{x}(P)$ must be non-decreasing. If $\hat{x}(P)$ is strictly monotone everwhere, then it is invertible, $P$ is informationally equivalent to $\hat{x}(P)=z$, and we arrive at the equilibrium characterized above. Suppose therefore that $\hat{x}(P)$ is flat over some range, i.e. $\hat{x}(P)=\hat{x}$ for $P \in\left(P^{\prime}, P^{\prime \prime}\right)$. Suppose further that for sufficiently low 
$\varepsilon>0, \hat{x}(P)$ is strictly increasing over $\left(P^{\prime}-\varepsilon, P^{\prime}\right)$ and $\left(P^{\prime \prime}, P^{\prime \prime}+\varepsilon\right)$, and hence uniquely invertible. ${ }^{35}$ But then for $z \in\left(\hat{x}\left(P^{\prime}-\varepsilon\right), \hat{x}\right)$ and $z \in\left(\hat{x}, \hat{x}\left(P^{\prime \prime}+\varepsilon\right)\right), P(z)$ is uniquely defined, and must be characterized as above, from the indifference condition for $\hat{x}(P)=z$. But since the function $P(z, k)$ defined above is continuous and strictly monotonic in $z$, it must be the case that $P^{\prime}=P^{\prime \prime}$, contradicting the existence of an interval for which $\hat{x}(P)$ is flat.

\section{Proof of Proposition 2:}

To simplify notation, let $\Upsilon=\alpha(\mathbb{E}(\mathbb{E}(R(\theta) \mid x=z, z)) / \mathbb{E}(R(\theta))-1)$. We begin with the results concerning $\hat{k} / k^{*}$. Since $\hat{k} / k^{*}=(1+\Upsilon)^{1 / \chi}$, it is immediate that $\hat{k} / k^{*}$ is increasing in $\Upsilon$, equal to 1 if and only if $\Upsilon=0$, and unbounded as $\Upsilon \rightarrow \infty$. Moreover, $\partial\left(\hat{k} / k^{*}\right) / \partial \chi^{-1}=\log (1+\Upsilon)(1+\Upsilon)^{1 / \chi}$, which is positive if and only if $\Upsilon>0$. Hence $\hat{k} / k^{*}$ is decreasing in $\chi$, if $\Upsilon<0$ and increasing in $\chi$, if $\Upsilon>0$, which proves that investment distortions are worse, the lower is $\chi$. Finally, if $\Upsilon>0$, then clearly $\hat{k} / k^{*}$ is unbounded as $\chi \rightarrow 0$, while if $\Upsilon<0, \hat{k} / k^{*} \geq(1-\alpha)^{1 / \chi}>0$.

Next consider comparative statics for $\Delta=1+(1+\Upsilon)^{1 / \chi}(\Upsilon / \chi-1)$ : Since

$$
\frac{\partial \Delta}{\partial \Upsilon}=\frac{1}{\chi} \frac{1+\chi}{\chi}(1+\Upsilon)^{1 / \chi} \frac{\Upsilon}{1+\Upsilon} \text { and } \frac{\partial \Delta}{\partial \chi^{-1}}=(1+\Upsilon)^{1 / \chi}(\Upsilon-\log (1+\Upsilon)(1-\Upsilon / \chi)),
$$

it follows that $\Delta=0$ iff $\Upsilon=0, \Delta$ is increasing in $\Upsilon$ (and therefore positive) if $\Upsilon>0$, and $\Delta$ is decreasing in $\Upsilon$ (and therefore again positive) if $\Upsilon<0$. Furthermore, $\frac{\partial \Delta}{\partial \chi^{-1}}>0$ if $\Upsilon / \chi \geq 1$, and $\frac{\partial \Delta}{\partial \chi^{-1}}=\Upsilon-\log (1+\Upsilon)(1-\Upsilon / \chi)>\Upsilon-\Upsilon(1-\Upsilon / \chi)>\Upsilon^{2} / \chi>0$ if $\Upsilon<\chi$. The limiting behavior, bounds, and the result that $\Delta>1$ if $\Upsilon>\chi$ also follow immediately.

We prove 3 and 4 for a slightly modification of our partial equilibrium model that also nests the general equilibrium model discussed in section 4. Specifically, suppose that incumbent shareholders select $k$ to maximize $\mathbb{E}\{\alpha \hat{Q} P(z ; k)+(1-\alpha) \Pi(\theta, k)\}$. Informed shareholders purchase whenever $\mathbb{E}(\Pi(\theta, k) \mid x, P) \geq Q P$, and the share price satisfies $P(z ; k)=Q^{-1} \cdot \mathbb{E}(\Pi(\theta, k) \mid x=z, z)$. Here, $Q^{-1}$ and $\hat{Q}^{-1}$ denote a market and incumbent shareholder discount rate between cash flows at stage 1 and stage 2 respectively. Our partial equilibrium formulation is nested by setting $Q=\hat{Q}=1$.

\section{Proof of Proposition 3:}

With the modified shareholder objective function, the implemented value of $k$ satisfies

$$
\alpha \frac{\hat{Q}}{Q} \mathbb{E}\left\{(1-\tau(z))\left(\mathbb{E}(R(\theta) \mid x=z, z)-C^{\prime}\left(k^{*}\right)\right)\right\}+(1-\alpha)\left(\mathbb{E}(R(\theta))-C^{\prime}\left(k^{*}\right)\right)=0 .
$$

\footnotetext{
${ }^{35}$ It cannot be flat everywhere, because then informed demand would be completely inelastic, and there would be no way to absorb noise trader shocks.
} 
A tax policy $\tau(z)$ implements $k^{*}$ if and only if $\mathbb{E}\left\{(1-\tau(z))\left(\mathbb{E}(R(\theta) \mid x=z, z)-C^{\prime}\left(k^{*}\right)\right)\right\}=0$, or equivalently $C^{\prime}\left(k^{*}\right)=\mathbb{E}(R(\theta))=\mathbb{E}\{(1-\hat{\tau}(z)) \mathbb{E}(R(\theta) \mid x=z, z)\}$. Therefore if $\hat{\tau}(z)$ implements $k^{*}$, then by construction the same is true for any $\tau(z)$, s.t. $1-\tau(z)=b(1-\hat{\tau}(z))$, with $b>0$. Condition (5) then follows from $\mathbb{E}(\hat{\tau}(z))=0$ and $\mathbb{E}\{\hat{\tau}(z) \mathbb{E}(R(\theta) \mid x=z, z)\}=$ $\operatorname{cov}(\hat{\tau}(z), \mathbb{E}(R(\theta) \mid x=z, z))$.

\section{Proof of Proposition 4:}

For a given intervention threshold $\hat{z}$, the first-order condition $\hat{k}$ is

$$
\alpha \frac{\hat{Q}}{Q} \int_{\hat{z}}^{\infty}\left(\mathbb{E}(R(\theta) \mid x=z, z)-C^{\prime}(\hat{k})\right) d \Phi\left(\sqrt{\lambda_{z}} z\right)+(1-\alpha)\left(\mathbb{E}(R(\theta))-C^{\prime}(\hat{k})\right)=0
$$

which corresponds to condition (6) with $\hat{Q}=Q=1$. The price floor at which the policy maker intervenes is equal to $\bar{P}=Q^{-1}(\mathbb{E}(R(\theta) \mid x=\hat{z}, \hat{z}) \hat{k}-C(\hat{k}))$. It then follows that $\hat{k}=k^{*}$ is implemented if and only if $\hat{z}=z^{*}$, which proves part $(i)$ of the proposition.

(ii) For each share bought, the policy maker earns a dividend $\Pi(\theta, \hat{k})$, but pays a price $\bar{P}$. Given $\theta$ and $u=\sqrt{\beta}(z-\theta)$, the policy maker purchases a measure $\alpha(\Phi(\sqrt{\beta}(\hat{x}-\theta))-\Phi(u))=$ $\alpha \operatorname{Pr}(x \in[z, \hat{x}] \mid \theta)$ of shares, where $\hat{x}$ is the informed traders' indifference threshold when the support price is active, i.e. whenever $z<\hat{z}$, which is defined by $Q \bar{P}=\mathbb{E}(\Pi(\theta, \hat{k}) \mid \hat{x}, z \leq \hat{z})$. Since $Q \bar{P}=\mathbb{E}(\Pi(\theta, \hat{k}) \mid x=\hat{z}, \hat{z})$, it follows that $\hat{x}>\hat{z}$. The expected number of shares purchased is equal to $\operatorname{Pr}(x \in[z, \hat{x}], z \leq \hat{z})$, while the expected dividend value equals

$$
\begin{aligned}
& \int_{-\infty}^{\infty} \int_{-\infty}^{\hat{z}} \Pi(\theta, \hat{k}) \operatorname{Pr}(x \in[z, \hat{x}] \mid \theta) d \Phi(\sqrt{\beta \delta}(z-\theta)) d \Phi(\sqrt{\lambda} \theta) \\
& =\mathbb{E}(\Pi(\theta, \hat{k}) \mid x \in[z, \hat{x}], z \leq \hat{z}) \cdot \operatorname{Pr}(x \in[z, \hat{x}], z \leq \hat{z})<Q \bar{P} \cdot \operatorname{Pr}(x \in[z, \hat{x}], z \leq \hat{z}) .
\end{aligned}
$$

Hence the policy maker's expected expenditure on equity shares $\bar{P} \cdot \operatorname{Pr}(x \in[z, \hat{x}], z \leq \hat{z})$ strictly exceeds expected dividends discounted at the market interest rate $Q$.

\section{Comparative statics for Equation 7:}

Equation (7) follows directly from the incumbent and final shareholders' FOCs. The final shareholder's welfare $u_{F}(\alpha V)-\alpha T=u_{F}(\alpha V)-\alpha V u_{F}^{\prime}(\alpha V)$ is increasing in $\alpha V$. In addition, $\alpha T=$ $\alpha V u_{F}^{\prime}(\alpha V)$ is increasing with $\alpha V$, since $-C \cdot u_{F}^{\prime \prime}(C) / u_{F}^{\prime}(C) \leq 1$ for all $C$. Applying the implicit function theorem to $\frac{u_{I}^{\prime}(V-\alpha V)}{v_{I}^{\prime}\left(\alpha V u_{F}^{\prime}(\alpha V)\right)}=u_{F}^{\prime}(\alpha V), \alpha V$ and $(1-\alpha) V$ must both be increasing with $V$, and therefore incumbent shareholder welfare $v_{I}(\alpha T)+u_{I}((1-\alpha) V)$ is also increasing in $V$. 


\section{Proof of Proposition 5:}

The first-order condition for $k_{G E}$ is

$$
\alpha_{0} \frac{\hat{Q}}{Q}\left(\mathbb{E}(\mathbb{E}(R(\theta) \mid x=z, z))-C^{\prime}\left(k_{G E}\right)\right)+\left(1-\alpha_{0}\right)\left(\mathbb{E}(R(\theta))-C^{\prime}\left(k_{G E}\right)\right)=0,
$$

where $\hat{Q}=1 / u_{F}^{\prime}\left(\alpha_{0} V_{G E}\right)$ satisfies

$$
\hat{Q}=\frac{v_{I}^{\prime}\left(\alpha_{0} T_{G E}\right)}{u_{I}^{\prime}\left(\left(1-\alpha_{0}\right) V_{G E}\right)}=\frac{V_{G E}}{T_{G E}}=\frac{(1+\chi) \mathbb{E}(R(\theta))-C^{\prime}\left(k_{G E}\right)}{(1+\chi) \mathbb{E}(\mathbb{E}(R(\theta) \mid x=z, z))-C^{\prime}\left(k_{G E}\right)} Q .
$$

(i) Suppose that $\mathbb{E}(\mathbb{E}(R(\theta) \mid x=z, z))>\mathbb{E}(R(\theta))$. We write the FOC for $C^{\prime}\left(k_{G E}\right)$ as

$$
\frac{\alpha_{0}}{1-\alpha_{0}}=\frac{C^{\prime}\left(k_{G E}\right)-\mathbb{E}(R(\theta))}{(1+\chi) \mathbb{E}(R(\theta))-C^{\prime}\left(k_{G E}\right)} \frac{(1+\chi) \mathbb{E}(\mathbb{E}(R(\theta) \mid x=z, z))-C^{\prime}\left(k_{G E}\right)}{\mathbb{E}(\mathbb{E}(R(\theta) \mid x=z, z))-C^{\prime}\left(k_{G E}\right)}
$$

As $\chi \rightarrow 0$, the second ratio converges to 1 , and therefore $C^{\prime}\left(k_{G E}\right) \approx\left(1+\alpha_{0} \chi\right) \mathbb{E}(R(\theta))$, and $Q / \hat{Q} \rightarrow \infty$. Expected dividends are $V_{G E} \approx \frac{\chi}{1+\chi} \mathbb{E}(R(\theta))^{1+1 / \chi}\left(1-\alpha_{0}\right)\left(1+\alpha_{0} \chi\right)^{1 / \chi}$ and therefore $V_{G E} / V^{*} \approx\left(1-\alpha_{0}\right)\left(1+\alpha_{0} \chi\right)^{1 / \chi} \rightarrow\left(1-\alpha_{0}\right) e^{\alpha_{0}}$.

(ii) Suppose that $\mathbb{E}(\mathbb{E}(R(\theta) \mid x=z, z))<\mathbb{E}(R(\theta))$. We write the FOC for $C^{\prime}\left(k_{G E}\right)$ as

$$
\frac{1-\alpha_{0}}{\alpha_{0}}=\frac{C^{\prime}\left(k_{G E}\right)-\mathbb{E}(\mathbb{E}(R(\theta) \mid x=z, z))}{(1+\chi) \mathbb{E}(\mathbb{E}(R(\theta) \mid x=z, z))-C^{\prime}\left(k_{G E}\right)} \frac{(1+\chi) \mathbb{E}(R(\theta))-C^{\prime}\left(k_{G E}\right)}{\mathbb{E}(R(\theta))-C^{\prime}\left(k_{G E}\right)}
$$

The second ratio converges to 1 as $\chi \rightarrow 0$, and therefore it follows that as $\chi \rightarrow 0, C^{\prime}\left(k_{G E}\right) \approx$ $\left(1+\left(1-\alpha_{0}\right) \chi\right) \mathbb{E}(\mathbb{E}(R(\theta) \mid x=z, z))$ and $Q / \hat{Q} \rightarrow 0$. Expected dividends are

$$
\begin{aligned}
\frac{V_{G E}}{(\mathbb{E}(\mathbb{E}(R(\theta) \mid x=z, z)))^{1+1 / \chi}} & \approx\left(\frac{\mathbb{E}(R(\theta))}{\mathbb{E}(\mathbb{E}(R(\theta) \mid x=z, z))}-\frac{1+\left(1-\alpha_{0}\right) \chi}{1+\chi}\right)\left(1+\left(1-\alpha_{0}\right) \chi\right)^{1 / \chi} \\
& \rightarrow\left(\frac{\mathbb{E}(R(\theta))}{\mathbb{E}(\mathbb{E}(R(\theta) \mid x=z, z))}-1\right) e^{1-\alpha_{0}}
\end{aligned}
$$

The expected dividends in the partial equilibrium benchmark are

$$
\begin{aligned}
& \frac{V_{P E}}{(\mathbb{E}(\mathbb{E}(R(\theta) \mid x=z, z)))^{1+1 / \chi}} \\
= & \left(\frac{\mathbb{E}(R(\theta))}{\mathbb{E}(\mathbb{E}(R(\theta) \mid x=z, z))}\left(1-\frac{1-\alpha_{0}}{1+\chi}\right)-\frac{\alpha_{0}}{1+\chi}\right)\left(1+\left(1-\alpha_{0}\right)\left(\frac{\mathbb{E}(R(\theta))}{\mathbb{E}(\mathbb{E}(R(\theta) \mid x=z, z))}-1\right)\right)^{1 / \chi}
\end{aligned}
$$

and therefore $V_{P E} /(\mathbb{E}(\mathbb{E}(R(\theta) \mid x=z, z)))^{1+1 / \chi} \rightarrow \infty$.

\section{Proof of Proposition 6:}

For any of the policy interventions considered, let $\left(T_{I}, V_{I}\right)$ and $\left(T_{F}, V_{F}\right)$ denote the aggregate market values and aggregate dividends from the perspective of incumbent and final shareholders. From the FOC w.r.t. $\alpha$ of incumbent shareholders, we have $T_{I} / V_{I}=\frac{u_{I}^{\prime}\left(C_{I}^{2}\right)}{v_{I}^{\prime}\left(C_{I}^{1}\right)}$ and $T_{F} / V_{F}=u_{F}^{\prime}\left(C_{F}^{2}\right)$. 
Intertemporal efficiency is satisfied if and only if $\hat{Q}=\frac{u_{I}^{\prime}\left(C_{I}^{2}\right)}{v_{I}^{\prime}\left(C_{I}^{1}\right)}=u_{F}^{\prime}\left(C_{F}^{2}\right)$, and therefore $T_{I} / V_{I}=$ $T_{F} / V_{F}$. Incumbent shareholders withdraw from equity markets if $\hat{Q} T_{I}<V_{I}$, while final shareholders withdraw if $V_{F} u_{F}^{\prime}\left(C_{F}^{2}\right)<T_{F}$. A situation of excess demand occurs if $V_{F} u_{F}^{\prime}\left(C_{F}^{2}\right)>T_{F}$, and final shareholders demand becomes arbitrarily high. Our proof evaluates for each of the policies and cases whether one of these cases arises.

(i) Since regulatory interventions do not affect market values (i.e. $T_{I}=T_{F}=T$ and $V_{I}=V_{F}=$ $V)$, it is automatically the case that $T_{I} / V_{I}=T_{F} / V_{F}$. Now, if $\mathbb{E}(\mathbb{E}(R(\theta) \mid x=z, z))>\mathbb{E}(R(\theta))$, market values must exceed $V / Q$, which is strictly positive. Since intertemporal MRS are aligned with market returns at $\hat{Q}$, the marked remains in equilibrium, i.e. situations of excess demand and supply or intertemporal distortions do not arise with regulation in the case of upside risk.

If instead $\mathbb{E}(\mathbb{E}(R(\theta) \mid x=z, z))<\mathbb{E}(R(\theta))$, then market values fall short of $V / Q$, and any intervention that increases $k$ must lower market values and eventually make them negative, because $k(\mathbb{E}(\mathbb{E}(R(\theta) \mid x=z, z))-C(k) / k)$ is decreasing and negative if $k$ is sufficiently large. Thus if $C(k) / k=\frac{1}{1+\chi} C^{\prime}(k) \geq \mathbb{E}(\mathbb{E}(R(\theta) \mid x=z, z))$, we have $T<0$, and the market inevitably shuts down. For small enough $\chi$, this occurs for any $k>k_{G E}$.

(ii) For transaction taxes we have $V_{I}=V_{F}=V$, but $T_{I}=Q^{-1} \mathbb{E}((1-\tau(z)) P(z, k))$ while $T_{F}=Q^{-1} \mathbb{E}(P(z, k))$. It follows that $T_{I}=T_{F}$ if and only if $\mathbb{E}(\tau(z) P(z, k))=0$. Suppose that $\mathbb{E}(\mathbb{E}(R(\theta) \mid x=z, z))>\mathbb{E}(R(\theta))$. Combining the first-order condition with financial transaction taxes with the characterization of $Q / \hat{Q}$ in general equilibrium implies that the same characterization of investment incentives applies except that $\mathbb{E}(\mathbb{E}(R(\theta) \mid x=z, z))$ is replaced with $\mathbb{E}((1-\hat{\tau}(z)) \mathbb{E}(R(\theta) \mid x=z, z))$. From the same steps as above, it follows that as long as $\mathbb{E}((1-\hat{\tau}(z)) \mathbb{E}(R(\theta) \mid x=z, z))>\mathbb{E}(R(\theta)), C^{\prime}\left(k_{G E}\right) \approx\left(1+\alpha_{0} \chi\right) \mathbb{E}(R(\theta))$ for small $\chi$, so the policy has no first-order effects on investment. Finally, suppose that the policy exactly implements first best $C^{\prime}(k)=\mathbb{E}(R(\theta))$. Revenue-neutrality requires that $\mathbb{E}(\tau(z) P(z, k))=0$, or $\mathbb{E}(\tau(z) \mathbb{E}(R(\theta) \mid x=z, z))=\mathbb{E}(\tau(z)) C(k) / k=\mathbb{E}(\tau(z)) \frac{1}{1+\chi} \mathbb{E}(R(\theta))$, while the implementation of $k^{*}$ requires $\mathbb{E}((1-\tau(z)) \mathbb{E}(R(\theta) \mid x=z, z))=\mathbb{E}((1-\tau(z))) \mathbb{E}(R(\theta))$. Combining these two equalities yields $\mathbb{E}(\mathbb{E}(R(\theta) \mid x=z, z))-\mathbb{E}(R(\theta))=-\mathbb{E}(R(\theta)) \mathbb{E}(\tau(z)) \frac{\chi}{1+\chi}$, which can hold in the limit as $\chi \rightarrow 0$ only if $\mathbb{E}(\tau(z)) \rightarrow-\infty$.

(iii) Suppose that $\mathbb{E}(\mathbb{E}(R(\theta) \mid x=z, z))<\mathbb{E}(R(\theta))$. For any policy such that $\mathbb{E}(R(\theta))>$ $\mathbb{E}((1-\hat{\tau}(z)) \mathbb{E}(R(\theta) \mid x=z, z))$, we have $C^{\prime}(k) \approx\left(1+\left(1-\alpha_{0}\right) \chi\right) \mathbb{E}((1-\hat{\tau}(z)) \mathbb{E}(R(\theta) \mid x=z, z))$ for small $\chi$. A tax policy that reduces downside risk therefore improves investment incentives. The tax revenue is $k Q^{-1}\left\{\mathbb{E}(\tau(z) \mathbb{E}(R(\theta) \mid x=z, z))-\mathbb{E}(\tau(z)) \frac{1}{1+\chi} C^{\prime}(k)\right\}$. Using the characterization 
of $C^{\prime}(k)$ and rearranging terms, this expression can be rewritten as

$$
k Q^{-1}\left\{\mathbb{E}(\mathbb{E}(R(\theta) \mid x=z, z))-\mathbb{E}((1-\hat{\tau}(z)) \mathbb{E}(R(\theta) \mid x=z, z))\left(1-\mathbb{E}(\tau(z)) \frac{\alpha_{0} \chi}{1+\chi}\right)\right\} .
$$

For small enough $\chi$, this expression is unambiguously negative for any tax policy such that $\mathbb{E}((1-\hat{\tau}(z)) \mathbb{E}(R(\theta) \mid x=z, z))>\mathbb{E}(\mathbb{E}(R(\theta) \mid x=z, z))$. Hence intertemporal distortions are unavoidable. The implied shareholder subsidy converges to $k\left\{C^{\prime}(k)-\mathbb{E}(\mathbb{E}(R(\theta) \mid x=z, z))\right\}>0$, and has the exact same size as a direct subsidy to investment.

The market value of equity for incumbent shareholders is $T_{I}=k Q^{-1} \mathbb{E}((1-\hat{\tau}(z)) \mathbb{E}(R(\theta) \mid x=z, z))\left\{\frac{\alpha_{0} \chi}{1+\chi}\right\}$, which converges to 0 as $\chi \rightarrow 0$. The aggregate price paid by final shareholders is

$$
T_{F}=k Q^{-1}\left\{\mathbb{E}(\mathbb{E}(R(\theta) \mid x=z, z))-\mathbb{E}((1-\hat{\tau}(z)) \mathbb{E}(R(\theta) \mid x=z, z)) \frac{1+\left(1-\alpha_{0}\right) \chi}{1+\chi}\right\}
$$

and must be strictly negative for small $\chi$. The subsidy on equity purchases thus exceeds the overall market value of equity, so that final shareholders pay a negative price for their equity stake, equity purchases are a free lunch for final shareholders. The transaction tax/subsidy policy thus causes an excess demand for equity.

(iv) Consider a market intervention with $\mathbb{E}(\mathbb{E}(R(\theta) \mid x=z, z))<\mathbb{E}(R(\theta))$. For any intervention threshold $\hat{z}$, we have $V_{I}=\mathbb{E}(\Pi(\theta, \hat{k})), Q T_{I}=Q \bar{P} \Phi\left(\sqrt{\lambda_{z}} \hat{z}\right)+\mathbb{E}(\Pi(\theta, \hat{k}) \mid x=z, z ; z \geq \hat{z})\left(1-\Phi\left(\sqrt{\lambda_{z}} \hat{z}\right)\right)$, $Q\left(T_{I}-T_{F}\right)=Q \bar{P} \cdot \operatorname{Pr}(x \in[z, \hat{x}], z \leq \hat{z})$, and $V_{I}-V_{F}=\mathbb{E}(\Pi(\theta, \hat{k}) \mid x \in[z, \hat{x}], z \leq \hat{z}) \cdot \operatorname{Pr}(x \in[z, \hat{x}], z \leq \hat{z})$. In addition, $Q \bar{P}=\mathbb{E}(\Pi(\theta, \hat{k}) \mid x=\hat{z}, \hat{z}) . \hat{k}$ solves the first-order condition

$$
\alpha_{0} \frac{\hat{Q}}{Q} \int_{\hat{z}}^{\infty}\left(\mathbb{E}(R(\theta) \mid x=z, z)-C^{\prime}(\hat{k})\right) d \Phi\left(\sqrt{\lambda_{z}} z\right)+\left(1-\alpha_{0}\right)\left(\mathbb{E}(R(\theta))-C^{\prime}(\hat{k})\right)=0 .
$$

For any $\hat{z} \leq z^{*}$, we obtain $C^{\prime}(\hat{k}) \geq \mathbb{E}(R(\theta) \mid x=z, z ; z \geq \hat{z})$, and therefore

$$
\begin{aligned}
Q T_{I} & =\hat{k}\left(\mathbb{E}(R(\theta) \mid x=\hat{z}, \hat{z}) \Phi\left(\sqrt{\lambda_{z}} \hat{z}\right)+\mathbb{E}(R(\theta) \mid x=z, z ; z \geq \hat{z})\left(1-\Phi\left(\sqrt{\lambda_{z}} \hat{z}\right)\right)-\frac{1}{1+\chi} C^{\prime}(\hat{k})\right) \\
& \leq \hat{k}\left(\mathbb{E}(R(\theta) \mid x=\hat{z}, \hat{z}) \Phi\left(\sqrt{\lambda_{z}} \hat{z}\right)+\mathbb{E}(R(\theta) \mid x=z, z ; z \geq \hat{z})\left(1-\Phi\left(\sqrt{\lambda_{z}} \hat{z}\right)-\frac{1}{1+\chi}\right)\right)
\end{aligned}
$$

which is unambiguously negative for sufficiently small $\chi$. Therefore, there is no intervention with a threshold $\hat{z} \leq z^{*}$ that does not cause incumbent shareholders to withdraw from the market.

Suppose next that $\hat{z}>z^{*}$. This implies that $\mathbb{E}(R(\theta))<C^{\prime}(\hat{k})<\mathbb{E}(R(\theta) \mid x=z, z ; z \geq \hat{z})$. Rewrite the first-order condition for $\hat{k}$ as

$$
\frac{\alpha_{0}}{1-\alpha_{0}}\left(1-\Phi\left(\sqrt{\lambda_{z}} \hat{z}\right)\right)=\frac{Q}{\hat{Q}} \frac{C^{\prime}(\hat{k})-\mathbb{E}(R(\theta))}{\mathbb{E}(R(\theta) \mid x=z, z ; z \geq \hat{z})-C^{\prime}(\hat{k})}
$$


where

$$
\frac{Q}{\hat{Q}}=\frac{\mathbb{E}(R(\theta) \mid x=\hat{z}, \hat{z}) \Phi\left(\sqrt{\lambda_{z}} \hat{z}\right)+\mathbb{E}(R(\theta) \mid x=z, z ; z \geq \hat{z})\left(1-\Phi\left(\sqrt{\lambda_{z}} \hat{z}\right)\right)-\frac{1}{1+\chi} C^{\prime}(\hat{k})}{\mathbb{E}(R(\theta))-\frac{1}{1+\chi} C^{\prime}(\hat{k})} .
$$

Therefore, define $z_{1}$ by

$$
\mathbb{E}(R(\theta))=\mathbb{E}\left(R(\theta) \mid x=z_{1}, z_{1}\right) \Phi\left(\sqrt{\lambda_{z}} z_{1}\right)+\mathbb{E}\left(R(\theta) \mid x=z, z ; z \geq z_{1}\right)\left(1-\Phi\left(\sqrt{\lambda_{z}} z_{1}\right)\right)
$$

as the intervention threshold at which the market return exactly matches the fundamental return, and note that $\mathbb{E}\left(R(\theta) \mid x=z, z ; z \geq z_{1}\right)>\mathbb{E}(R(\theta))>\mathbb{E}\left(R(\theta) \mid x=z_{1}, z_{1}\right)$. For any $\hat{z} \leq z_{1}$, we necessarily obtain that $Q T_{I} \leq 0$ for sufficiently small $\chi$, and hence that the policy intervention necessarily induces a market breakdown.

If instead $\hat{z} \geq z_{1}$, the intervention is so large that it transforms the investment return into an upside risk. As $\chi \rightarrow 0$, the first-order condition can be re-written as:

$$
\frac{\alpha_{0}}{1-\alpha_{0}} \Psi \approx \frac{C^{\prime}(\hat{k})-\mathbb{E}(R(\theta))}{\mathbb{E}(R(\theta))-\frac{1}{1+\chi} C^{\prime}(\hat{k})}
$$

where

$$
\Psi=\frac{\left(1-\Phi\left(\sqrt{\lambda_{z}} \hat{z}\right)\right)(\mathbb{E}(R(\theta) \mid x=z, z ; z \geq \hat{z})-\mathbb{E}(R(\theta)))}{\Phi\left(\sqrt{\lambda_{z}} \hat{z}\right)(\mathbb{E}(R(\theta) \mid x=\hat{z}, \hat{z})-\mathbb{E}(R(\theta)))+\left(1-\Phi\left(\sqrt{\lambda_{z}} \hat{z}\right)\right)(\mathbb{E}(R(\theta) \mid x=z, z ; z \geq \hat{z})-\mathbb{E}(R(\theta)))},
$$

Therefore, for small $\chi$, we have $C^{\prime}(\hat{k}) \approx(1+\hat{\alpha} \chi) \mathbb{E}(R(\theta))$, where $\hat{\alpha}=\alpha \Psi /(1-\alpha+\alpha \Psi)$. With this, we can characterize $Q T_{I}, Q T_{F}, V_{I}$, and $V_{F}$ :

$$
\begin{gathered}
Q T_{I}=\hat{k}\left\{\mathbb{E}(R(\theta) \mid x=\hat{z}, \hat{z}) \Phi\left(\sqrt{\lambda_{z}} \hat{z}\right)+\mathbb{E}(R(\theta) \mid x=z, z ; z \geq \hat{z})\left(1-\Phi\left(\sqrt{\lambda_{z}} \hat{z}\right)\right)-\frac{1+\hat{\alpha} \chi}{1+\chi} \mathbb{E}(R(\theta))\right\} \\
V_{I}=\hat{k} \mathbb{E}(R(\theta))\left\{1-\frac{1+\hat{\alpha} \chi}{1+\chi}\right\}=\hat{k} \mathbb{E}(R(\theta)) \frac{(1-\hat{\alpha}) \chi}{1+\chi} \\
Q T_{F}=Q T_{I}-\hat{k} \cdot \operatorname{Pr}(x \in[z, \hat{x}], z \leq \hat{z}) \cdot\left\{\mathbb{E}(R(\theta) \mid x=\hat{z}, \hat{z})-\frac{1+\hat{\alpha} \chi}{1+\chi} \mathbb{E}(R(\theta))\right\} \\
V_{F}=V_{I}-\hat{k} \cdot \operatorname{Pr}(x \in[z, \hat{x}], z \leq \hat{z}) \cdot\left\{\mathbb{E}(R(\theta) \mid x \in[z, \hat{x}], z \leq \hat{z})-\frac{1+\hat{\alpha} \chi}{1+\chi} \mathbb{E}(R(\theta))\right\} .
\end{gathered}
$$

It is straight-forward to check that $Q T_{I}>0$ and $Q T_{F}>0$, and $T_{I} \gtreqless T_{F}$, if and only if $\mathbb{E}(R(\theta) \mid x=\hat{z}, \hat{z}) \gtreqless$ $\frac{1+\hat{\alpha} \chi}{1+\chi} \mathbb{E}(R(\theta))$. Moreover, $T_{I} / T_{F}$ reaches a positive finite limit as $\chi \rightarrow 0$, for any $\hat{z}>\widetilde{z}$.

At the same time, $V_{I} \rightarrow 0$ as $\chi \rightarrow 0$. Let $z_{2}$ solve $\mathbb{E}\left(R(\theta) \mid x \in[z, \hat{x}], z \leq z_{2}\right)=\mathbb{E}(R(\theta))$. If $\hat{z}=z_{2}, V_{F}=V_{I}$. But since at $\hat{z}=z_{2}$, we have $\mathbb{E}(R(\theta) \mid x=\hat{z}, \hat{z})>\mathbb{E}\left(R(\theta) \mid x \in[z, \hat{x}], z \leq z_{2}\right)=$ 
$\mathbb{E}(R(\theta))$, it follows that $T_{I}>T_{F}$, so that the intervention leads to an intertemporal distortion. If instead $\hat{z}>z_{2}$, it follows that $V_{F}<0$ for sufficiently low $\chi$, causing final shareholders to withdraw from the equity market, and resulting in a market breakdown with excess supply of shares.

Finally, if $\hat{z} \in\left(z_{1}, z_{2}\right), V_{F}$ reaches a positive, finite limit as $\chi \rightarrow 0$. Since $Q \sim 1 / V_{I}$ becomes infinitely large, but $Q T_{I}$ and $Q T_{F}$ both reach positive finite limist as $\chi \rightarrow 0$, it must be the case that $T_{F} \rightarrow 0$. But then $V_{F} / T_{F} \rightarrow \infty$, and demand by final shareholders must be unboundedly large, resulting in excess demand for shares.

\section{Proof of Proposition 7:}

Let $\omega(\hat{\theta})$ denote the leverage ratio $\frac{w}{k}$ that satisfies (14) with equality. Then the incumbent shareholder's return takes the form

$\rho(\omega(\hat{\theta}) ; \hat{\theta})=(1 / \omega(\hat{\theta})) \int_{\hat{\theta}}^{\infty}(R(\theta)-R(\hat{\theta})) d \Phi\left(\sqrt{\lambda_{P}} \theta\right)=(1 / \omega(\hat{\theta})) \int_{\hat{\theta}}^{\infty} R^{\prime}(\theta)\left(1-\Phi\left(\sqrt{\lambda_{P}} \theta\right)\right) d \theta$.

The optimal choice of $\hat{\theta}$ satisfies the first-order condition

$$
0=\frac{d \ln \rho(\omega(\hat{\theta}) ; \hat{\theta})}{d \hat{\theta}}=\frac{-R^{\prime}(\hat{\theta})\left(1-\Phi\left(\sqrt{\lambda_{P}} \hat{\theta}\right)\right)}{\int_{\hat{\theta}}^{\infty} R^{\prime}(\theta)\left(1-\Phi\left(\sqrt{\lambda_{P}} \theta\right)\right) d \theta}-\frac{\omega^{\prime}(\hat{\theta})}{\omega(\hat{\theta})},
$$

along with the second order condition $\frac{d^{2} \ln \rho(\omega(\hat{\theta}) ; \hat{\theta})}{d \hat{\theta}^{2}}<0$.

(i) With $\bar{R}>2$ and $\lambda_{P}=\lambda$, there exists an optimal threshold $\hat{\theta}$ at which the lender's break-even condition is satisfied and the borrower's return exceeds 1 . We thus need to show that a lower value of $\lambda_{P}$ strictly increases borrower returns for given $\hat{\theta}$ and $w / k$, and increases the optimal choice of $\hat{\theta}$ and $w / k$. Borrower returns are decreasing in $\sqrt{\lambda_{\mathbf{P}}}$ since

$$
\frac{\partial}{\partial \sqrt{\lambda_{P}} \theta} \int_{\hat{\theta}}^{\infty} R^{\prime}(\theta)\left(1-\Phi\left(\sqrt{\lambda_{P}} \theta\right)\right) d \theta=-\int_{\hat{\theta}}^{\infty} R^{\prime}(\theta) \theta \phi\left(\sqrt{\lambda_{P}} \theta\right) d \theta
$$

is negative for any symmetric $R$. The optimal choice of $\hat{\theta}$ is decreasing in $\sqrt{\lambda_{P}}$ whenever $\frac{\partial \ln \rho(\omega(\hat{\theta}) ; \hat{\theta})}{\partial \hat{\theta}}$ is decreasing in $\sqrt{\lambda_{P}}$. But

$$
\frac{\partial^{2} \ln \rho(\omega(\hat{\theta}) ; \hat{\theta})}{\partial \hat{\theta} \partial \sqrt{\lambda_{P}}}=\frac{-R^{\prime}(\hat{\theta})\left(1-\Phi\left(\sqrt{\lambda_{P}} \hat{\theta}\right)\right)}{\int_{\hat{\theta}}^{\infty} R^{\prime}(\theta)\left(1-\Phi\left(\sqrt{\lambda_{P}} \theta\right)\right) d \theta}\left\{\frac{\int_{\hat{\theta}}^{\infty} R^{\prime}(\theta) \theta \phi\left(\sqrt{\lambda_{P}} \theta\right) d \theta}{\int_{\hat{\theta}}^{\infty} R^{\prime}(\theta)\left(1-\Phi\left(\sqrt{\lambda_{P}} \theta\right)\right) d \theta}-\frac{\hat{\theta} \phi\left(\sqrt{\lambda_{P}} \hat{\theta}\right)}{1-\Phi\left(\sqrt{\lambda_{P}} \hat{\theta}\right)}\right\}
$$

is negative whenever the term in brackets is positive, which is straight-forward to check for $\hat{\theta}<0$, and follows from the fact that $u \phi(u) /(1-\Phi(u))$ is strictly increasing in $u$ for $u>0$.

(ii) As $\lambda_{P} \rightarrow 0, \rho\left(\frac{w}{k} ; \hat{\theta}\right)$ converges to $(1 / \omega(\hat{\theta})) \frac{1}{2}(\bar{R}-R(\hat{\theta}))$. The incumbent shareholders will then choose to borrow if for some $\hat{\theta}$,

$$
\frac{1}{2}(\bar{R}-R(\hat{\theta}))>\omega(\hat{\theta})=1-\mathbb{E}(R(\theta))+\varepsilon \int_{-\infty}^{\hat{\theta}} R(\theta) d \Phi(\sqrt{\lambda} \theta)+\int_{\hat{\theta}}^{\infty}(R(\theta)-R(\hat{\theta})) d \Phi(\sqrt{\lambda} \theta),
$$


or equivalently

$$
\begin{aligned}
\bar{R} & >\min _{\hat{\theta}}\left\{2-2(1-\varepsilon) \int_{-\infty}^{\hat{\theta}} R(\theta) d \Phi(\sqrt{\lambda} \theta)-R(\hat{\theta})(1-2 \Phi(\sqrt{\lambda} \hat{\theta}))\right\} \\
& =2-\bar{R} \max _{\hat{\theta}} \int_{-\infty}^{\hat{\theta}}\{1-2 \varepsilon \Phi(\sqrt{\lambda} \hat{\theta})-2(1-\varepsilon) \Phi(\sqrt{\lambda} \theta)\} R_{0}^{\prime}(\theta) d \theta
\end{aligned}
$$

where $R_{0}(\theta)=R(\theta) / \bar{R}$ normalizes $R(\theta)$ to the interval $[0,2]$ and has expected value $\mathbb{E}\left(R_{0}(\theta)\right)=1$. Since $\int_{-\infty}^{\hat{\theta}}\{1-2 \varepsilon \Phi(\sqrt{\lambda} \hat{\theta})-2(1-\varepsilon) \Phi(\sqrt{\lambda} \theta)\} R_{0}^{\prime}(\theta) d \theta>0$ for all $\hat{\theta} \leq 0$ there exists

$$
\tilde{R}\left(\varepsilon ; R_{0}(\cdot)\right)=\frac{2}{1+\max _{\hat{\theta}} \int_{-\infty}^{\hat{\theta}}\{1-2 \varepsilon \Phi(\sqrt{\lambda} \hat{\theta})-2(1-\varepsilon) \Phi(\sqrt{\lambda} \theta)\} R_{0}^{\prime}(\theta) d \theta}<2
$$

and whenever $\bar{R} \in\left(\tilde{R}\left(\varepsilon ; R_{0}(\cdot)\right) ; 2\right)$, the incumbent shareholders prefer to borrow and invest, even though the expected returns from investing are strictly less than 1.

\section{Proof of Proposition 8:}

From the first-order condition $(1+b) C^{\prime}(\hat{k})=\mathbb{E}(\mathbb{E}(R(\theta) \mid x=z, z)), \hat{k}$ is decreasing in $b$. Substituting the FOC into expected dividends we obtain

$$
V=\mathbb{E}(R(\theta)) \hat{k}-(1+b) C(\hat{k})=\left\{\mathbb{E}(R(\theta))-\frac{1}{1+\chi} \mathbb{E}(\mathbb{E}(R(\theta) \mid x=z, z))\right\} \hat{k}
$$

which is decreasing in $\hat{k}$ and increasing in $b$, whenever $\mathbb{E}(\mathbb{E}(R(\theta) \mid x=z, z)) / \mathbb{E}(R(\theta))>1+\chi$.

\section{Proof of Proposition 9:}

(i) Let $y^{\prime}$ be such that $\mathbb{E}\left(\mathbb{E}\left(R(\theta) \mid x=z, z, y^{\prime}\right) \mid y^{\prime}\right)=\mathbb{E}(\mathbb{E}(R(\theta) \mid x=z, z))$. We write $V(y) / V$ as

$$
\frac{V(y)}{V}=\left(\frac{\mathbb{E}(\mathbb{E}(R(\theta) \mid x=z, z, y) \mid y)}{\mathbb{E}(\mathbb{E}(R(\theta) \mid x=z, z))}\right)^{1 / \chi} \frac{\mathbb{E}(\mathbb{E}(R(\theta) \mid x=z, z, y) \mid y)-(1+\chi) \mathbb{E}(R(\theta) \mid y)}{\mathbb{E}(\mathbb{E}(R(\theta) \mid x=z, z))-(1+\chi) \mathbb{E}(R(\theta))}
$$

Since $R(\cdot)$ is convex, $\mathbb{E}(\mathbb{E}(R(\theta) \mid x=z, z))>\mathbb{E}(R(\theta))$ and $\mathbb{E}(\mathbb{E}(R(\theta) \mid x=z, z, y) \mid y)>\mathbb{E}(R(\theta) \mid y)$ for all $y$. Therefore,

$\lim _{\chi \rightarrow 0} \frac{\mathbb{E}(\mathbb{E}(R(\theta) \mid x=z, z, y) \mid y)-(1+\chi) \mathbb{E}(R(\theta) \mid y)}{\mathbb{E}(\mathbb{E}(R(\theta) \mid x=z, z))-(1+\chi) \mathbb{E}(R(\theta))}=\frac{\mathbb{E}(\mathbb{E}(R(\theta) \mid x=z, z, y) \mid y)-\mathbb{E}(R(\theta) \mid y)}{\mathbb{E}(\mathbb{E}(R(\theta) \mid x=z, z))-\mathbb{E}(R(\theta))}>0$.

But then $\lim _{\chi \rightarrow 0} V(y) / V=0$ for all $y<y^{\prime}$ and $\lim _{\chi \rightarrow 0} V(y) / V=\infty$ for all $y>y^{\prime}$. Since $\operatorname{Pr}\left(y>y^{\prime}\right)>0$, it follows that $\lim _{\chi \rightarrow 0} \mathbb{E}(V(y)) / V=\infty$. At the same time, we know that $V<0$ and therefore $\mathbb{E}(V(y))<V<0$ for sufficiently low $\chi$.

(ii) We have $\mathbb{E}(P(z, \hat{k}))=\frac{\chi}{1+\chi}\{\mathbb{E}(\mathbb{E}(R(\theta) \mid x=z, z))\}^{1+1 / \chi}$ and $\mathbb{E}(P(z, y, \hat{k}(y)) \mid y)=$ $\frac{\chi}{1+\chi}\{\mathbb{E}(\mathbb{E}(R(\theta) \mid x=z, z, y) \mid y)\}^{1+1 / \chi}$ and therefore $\lim _{\chi \rightarrow 0} \mathbb{E}(P(z, y, \hat{k}(y)) \mid y) / \mathbb{E}(P(z, \hat{k}))=$ $\infty$ for all $y>y^{\prime}$. 


\section{Proof of Proposition 10:}

Follows directly from the arguments in the text and the assumption that $\mathbb{E}(R(\theta) \mid x=z, z) / \mathbb{E}(R(\theta) \mid z)$ is strictly increasing

\section{Proof of Proposition 11:}

Consider a small perturbation of investment parametrized by $\left(\eta_{I}, \eta_{F}\right)$, such that

$d k_{I}=\eta_{I}\left\{\mathbb{E}\left(R_{I}(\theta)\right)-\mathbb{E}\left[\mathbb{E}\left(R_{I}(\theta) \mid x=z, z\right)\right]\right\}$ and $d k_{F}(z)=\eta_{F}\left(\mathbb{E}\left(R_{F}(\theta) \mid x=z, z\right)-\mathbb{E}\left(R_{F}(\theta) \mid z\right)\right)$

The final shareholders' expected payoff is

$$
\left\{\mathbb{E}\left(R_{I}(\theta)\right)-\mathbb{E}\left[\mathbb{E}\left(R_{I}(\theta) \mid x=z, z\right)\right]\right\} k_{I}+\mathbb{E}\left\{k_{F}(z)\left(\mathbb{E}\left(R_{F}(\theta) \mid z\right)-\mathbb{E}\left(R_{F}(\theta) \mid x=z, z\right)\right)\right\},
$$

and therefore their welfare is unchanged if

$$
d k_{I}\left\{\mathbb{E}\left(R_{I}(\theta)\right)-\mathbb{E}\left[\mathbb{E}\left(R_{I}(\theta) \mid x=z, z\right)\right]\right\}=-\mathbb{E}\left\{d k_{F}(z)\left(\mathbb{E}\left(R_{F}(\theta) \mid z\right)-\mathbb{E}\left(R_{F}(\theta) \mid x=z, z\right)\right)\right\},
$$

or

$$
\frac{\eta_{I}}{\eta_{F}}=\frac{\mathbb{E}\left\{\left(\mathbb{E}\left(R_{F}(\theta) \mid z\right)-\mathbb{E}\left(R_{F}(\theta) \mid x=z, z\right)\right)^{2}\right\}}{\left\{\mathbb{E}\left(R_{I}(\theta)\right)-\mathbb{E}\left[\mathbb{E}\left(R_{I}(\theta) \mid x=z, z\right)\right]\right\}^{2}} .
$$

The incumbent shareholders' expected payoff is

$$
\begin{aligned}
& \mathbb{E}\left[\mathbb{E}\left(R_{I}(\theta) \mid x=z, z\right)\right] k_{I}-C_{I}\left(k_{I}\right)+\mathbb{E}\left\{k_{F}(z) \mathbb{E}\left(R_{F}(\theta) \mid x=z, z\right)\right\}-\mathbb{E}\left\{C_{F}\left(k_{F}(z)\right)\right\} \\
= & \mathbb{E}\left[\mathbb{E}\left(R_{I}(\theta) \mid x=z, z\right)\right] k_{I}-C_{I}\left(k_{I}\right)+\mathbb{E}\left\{\mathbb{E}\left(R_{F}(\theta) \mid z\right) k_{F}(z)\right\}-\mathbb{E}\left\{C_{F}\left(k_{F}(z)\right)\right\} \\
& +\mathbb{E}\left\{k_{F}(z)\left(\mathbb{E}\left(R_{F}(\theta) \mid x=z, z\right)-\mathbb{E}\left(R_{F}(\theta) \mid z\right)\right)\right\}
\end{aligned}
$$

Therefore the change in expected payoffs resulting from the perturbation is

$$
\begin{aligned}
& \left\{\mathbb{E}\left[\mathbb{E}\left(R_{I}(\theta) \mid x=z, z\right)\right]-C_{I}^{\prime}\left(k_{I}\right)\right\} d k_{I}+\mathbb{E}\left\{\left(\mathbb{E}\left(R_{F}(\theta) \mid z\right)-C_{F}^{\prime}\left(k_{F}(z)\right)\right) d k_{F}(z)\right\} \\
& +\mathbb{E}\left\{d k_{F}(z)\left(\mathbb{E}\left(R_{F}(\theta) \mid x=z, z\right)-\mathbb{E}\left(R_{F}(\theta) \mid z\right)\right)\right\}
\end{aligned}
$$

From the first-order conditions defining $k_{I}$ and $k_{F}(z)$, the first two terms are zero, while the third term equals $\eta_{F} \mathbb{E}\left\{\left(\mathbb{E}\left(R_{F}(\theta) \mid z\right)-\mathbb{E}\left(R_{F}(\theta) \mid x=z, z\right)\right)^{2}\right\}>0$, which shows that incumbent shareholders are made strictly better off by the perturbation. 